\title{
Article \\ The Mechanism of Driving Green Growth and Decreasing Energy Security Risks by Innovation in China
}

\author{
Feng Wang and Ruiqi Wang *D \\ School of Economics and Finance, Xi'an Jiaotong University, Xi'an 710061, China; wangfeng123@xjtu.edu.cn \\ * Correspondence: wangruiqi1994@stu.xjtu.edu.cn
}

check for updates

Citation: Wang, F.; Wang, R. The Mechanism of Driving Green Growth and Decreasing Energy Security Risks by Innovation in China. Sustainability 2021, 13, 4733. https://doi.org/ $10.3390 /$ su13094733

Academic Editors: Brantley Liddle and Peter Burgherr

Received: 14 March 2021

Accepted: 20 April 2021

Published: 23 April 2021

Publisher's Note: MDPI stays neutral with regard to jurisdictional claims in published maps and institutional affiliations.

Copyright: (C) 2021 by the authors. Licensee MDPI, Basel, Switzerland. This article is an open access article distributed under the terms and conditions of the Creative Commons Attribution (CC BY) license (https:// creativecommons.org/licenses/by/ $4.0 /)$.

\begin{abstract}
The role of innovation for economic growth has been proved by studies. However, whether innovation can decrease environmental cost and energy security risks remains to be studied. To explore the theoretical mechanism of driving green economic growth by innovation, we constructed a four-sector endogenous growth model, including the final-goods sector, the intermediate-goods sector, the Research and Development (R\&D) sector, and the energy sector. Then we measured the innovation-driven effect of green growth and calculated the green added value of 40 industries in China during 2005-2016. Based on the calculations, we used a threshold regression model to test the mechanism of driving green growth and decreasing energy security risks by innovation. The results showed that: (1) the innovation-driven effect on green growth increased from 0.2729 in 2005 to 0.3446 in 2016. (2) The proportion of green added value in the traditionally added value increased from $79.54 \%$ in 2005 to $92.25 \%$ in 2016. (3) Innovation had a threshold effect on green growth: the role of innovation in driving green growth weakened in the long term, but not in the short term (4) Innovation also had a threshold effect on energy security risk: after the innovation-driven effect crossed the threshold, innovation decreased energy security risk more significantly.
\end{abstract}

Keywords: innovation driven; green growth; energy security risk; mechanism

\section{Introduction}

Energy is a material basis for human survival and development. However, while promoting the progress of human civilization, the overuse of energy makes the countries confronted with a severe situation of resource exhaustion and environmental pollution, which restricts their sustainable development. For developing countries, the overuse of energy is mainly caused by the extensive development model. Besides the overuse of energy, this model also brings these countries with severe resource and environmental problems. Identical to the other developing countries, China's extensive development mode also brought China severe resource and environmental problems and made China the largest energy consumer and the largest carbon emitter in the world. It indicates that studying green growth in China can achieve China's sustainable development, provide a reference for other developing countries' green growth, and control global carbon emissions to a certain extent.

In the fossil-energy era, economic development is highly dependent on energy. To maintain the stability of economic development, countries all over the world have formulated energy security strategies to maintain their energy supply. For China, oil and gas resources in China are relatively scarce, so the huge energy consumption brought by the extensive development mode ultimately leads to the high dependency on imported energy; according to BP Statistical Review of World Energy [1], China's external dependence on oil and natural gas reached $72 \%$ and $43 \%$ respectively in 2018 . It means that China is also confronted with aggravating energy security risks. From the international experience, developed countries, due to their economic and technological advantages, can ensure their energy security by promoting the use of renewable energy. However, developing countries have backward 
technology, so they can only adopt extensive development models to develop the economy, which leads to higher energy security risks. China has been the second-largest economy and one of the largest developing countries in the world. The study of China's energy security can not only ensure China's energy security but also provide a reference for other developing countries in formulating energy security strategies.

The above analysis indicates, to alleviate the environmental pressure and decrease energy security risk, China should transform development mode and achieve sustainable development. In the New Normal of China's economy, economic growth has shifted gear from the previous high speed to a medium-to-high one [2]. Relevant research indicates that the economic growth slows because technological progress slows, the capital accumulation speed declines, demographic dividend disappears, and so on [3]. We can see that the pivotal driving forces (such as investment, consumption, and export) are not enough to support the high-speed operation in the economy, so China should cultivate new driving forces of economic growth [4,5]. The innovation-driven development strategy is considered an essential measure to reshape the growth drivers. In the face of the increasing environmental pressure and energy security risks, studying the influence of innovation on green economic growth (for the sake of brevity, green economic growth was called green growth in the following text) and energy security risk is necessary. Existing studies indicate that innovation will promote green growth by decreasing environmental pollution and resource consumption. In the meanwhile, external dependence on energy will decrease as resource consumption declines, which decreases energy security risks. Therefore, we assume that innovation will promote green growth and decrease the risk of energy security. In the following analysis, we will prove this hypothesis through theoretical and empirical models.

Abundant literature has studied the impact of innovation on green growth, and the literature can be divided into the following three aspects. First, some literature studies the impact of innovation on green growth. Pan et al. [6] suggested that sustainable development in China should be promoted through technological progress. From the perspective of cities, Liu and Dong [7] discussed the relationship between innovation and green economy efficiency in China and found the intensive effect of innovation could improve green economy efficiency. Second, some studies classify technological progress and study the impact of various types of technological progress on green growth. Yan et al. [8] discussed the effect of renewable energy technology innovation on China's green productivity and found this effect was nonlinear. Mensah et al. [9] examined the impact of technological innovation on the green growth of 28 Organization for Economic Cooperation and Development (OECD) economies from 2000 to 2014 and indicated that there were differences in the impact of different technologies on green growth. Third, some studies focus on the relationship between innovation, environmental regulation, and green growth. Guo et al. [10] examined this relationship and denoted that properly designed environmental regulation would positively affect green growth through motivating innovation. Du et al. [11] found that environmental regulation would restrain the development of green technology innovation when the economic development levels are low, but not when the economic development levels tend to be high.

For the studies on energy security, current studies prefer to measure energy security rather than examine the relationship between innovation and energy security. To be specific, the literature on energy security can also be divided into the following three aspects. First, some literature chooses to measure energy security from the perspective of countries. $\mathrm{Hu}$ and Ge [12] constructed an evaluation model to evaluate China's geo-energy security level from 1995 to 2010. Fang et al. [13] built the index model to evaluate the level of China's energy security from 2005 to 2015. Second, besides whole countries, some studies also take regions, provinces, and cities as research objects. Zhang et al. [14] analyzed the energy security of provinces in China and concluded that all provinces were facing threats related to energy availability and diversity. Sun et al. [15] found that regional energy security in China lay at a low and medium level. Third, the energy security of a specific energy source also received increasing interest in the academic literature. Yang et al. [16] constructed the 
coal security index system to evaluate the level of coal security of 31 provinces and found that this index declined in the early stage but rose slowly in recent years. Although previous studies of energy security have not dealt with the impact of innovation on energy security, there is a broad consensus that energy security can be ensured by promoting the utilization of renewable energy through innovation. Therefore, innovation can be regarded as an effective approach to decrease the risk of energy security.

It can be seen that although extensive research has been carried out on green growth and energy security, little research explores the mechanism driving green growth and decreasing energy security risk by innovation. So there are some issues to be solved: (1) How does innovation drive green growth in the economy? (2) How to measure the driven effect of innovation on green growth? (3) How to measure industrial green growth? (4) What is the mechanism of driving green growth and decreasing energy security risks by innovation? (5) Which factors affect this mechanism? To answer these questions, first, we expanded the endogenous growth model proposed by Romer [17] and explored the theoretical mechanism of driving green growth by innovation. Considering that innovation may decrease energy security risk by promoting clean energy production, we included the energy sector into the endogenous growth model. Second, based on our model and industrial data, we measured the innovation-driven effect of 40 industries in China from 2005 to 2016 and investigated the evolution characteristics of the effect. Third, based on the System of Environmental-Economic Accounting (SEEA), we calculated the green added value and analyzed their industry characteristics. Finally, using a threshold regression model, we studied the mechanism of driving green economic growth and decreasing energy security risks by innovation. Our conclusions have vital theoretical and practical value for implementing innovation-driven development strategies, facilitating green growth, and strengthening energy security in China.

Compared with the previous studies, this paper contributes marginally in the following three aspects: (1) We innovated the theoretical model; although the relevant studies have discussed the driven effect of innovation on economic development [12,18], few studies explore the theoretical mechanism of driving green growth by innovation, let alone include the energy sector in the endogenous growth model. To explore the theoretical mechanism of driving green growth by innovation, we introduced energy consumption and environmental quality into the production function and constructed a four-sector endogenous growth model including the final-goods sector, the intermediate-goods sector, the Research and Development (R\&D) sector, and the energy sector. (2) We expanded the research content on green added value. Due to the data limitation, the relevant studies around green growth focus on regions or a single industry. To supplement the existing research, we estimate the green added values of each industry based on the SEEA. (3) We expanded the research perspective and content of energy security risk. On the one hand, most research on energy security risk uses qualitative analyses. We identified the factors that affect energy security risk through a literature review and empirically test the impact of these factors on energy security risk. On the other hand, the relevant researches on energy security risk focus on the countries, regions, and provinces. Considering industrial developments ultimately influence energy security by affecting energy demand and consumption, we discuss the mechanism of decreasing energy security risks by innovation from the industrial perspective.

The remainder of this paper is arranged as follows: In Section 2, we constructed the endogenous growth model and measured the innovation-driven effect based on the industrial perspective; in Section 3, we estimated the green added values of each industry based on the SEEA; in Section 4, based on the measurement, we examined the mechanism of driving green growth and decreasing energy security risks by innovation. The conclusions and policy implications are listed in Section 5. 


\section{Model Construction and Measurement of Innovation-Driven Effect}

Before we construct the endogenous growth model, it is necessary to clarify the connotation of green growth and energy security.

As the international awareness of environmental problems grew rapidly since the World Commission on Environment and Development (WCED) [19] first presented "sustainable development" in 1987. Based on this concept, in 2009, the OECD proposed "green growth" [20]. Although relevant studies have been carried out since the 1980s, the connotations of green growth have not yet been unified [21]. According to the OECD [22], green growth is a growth mode that ensures the continuous supply of resources and environmental services at the same time as economic development. Because this connotation summarizes the environmentally friendly nature of green growth, we adopt it to define green growth.

Different from green growth, energy security did not receive attention until the first oil crisis. In this crisis, governments realized the importance of energy supply in maintaining the stability of the country. Since then, energy security has drawn the great attention of academia. In 1974, the International Energy Agency (IEA) first proposed "energy security" with the core of stabilizing crude oil supply and price [23]. Energy security is a proposition covering global economy and social development, political and diplomatic relations, so its connotation has not achieved a broad consensus. The traditional connotation of energy security only covers the security of energy supply and energy price [23]. With the increasingly severe resource and environmental problems, in addition to the above two connotations, environmental security has been widely concerned. According to the definition of the United Nations Development Program [24], energy security should be "the availability of energy in any form, sufficient quantity and reasonable price at any time, without irreversible negative impact on the environment". This definition covers the above three connotations, so it has been widely recognized by academics. Furthermore, some scholars noted the relationship between energy security and energy security risk. Zhang and Xiao [25] believed that energy security was the ability of a country to deal with the risks associated with it. Specifically, this ability covers preventing risks, maintaining survival, and ensuring development. It can be seen that energy supply security, energy price security, and environmental security are the connotations of energy security and also reflect energy security risks.

Before constructing the theoretical model, we need to elaborate on Romer's endogenous growth model [17] systematically. In this model, there are three sectors in the economy, which are the final goods sector, the intermediate-goods sector, the research sector. Specifically, the research sector is the sector which produces a new design of intermediate goods and increases knowledge stock, the intermediate-goods sector is the sector which purchases new design from the research sector, produces intermediate goods and sell them to the final goods sector, and the final goods sector is the sector which purchases intermediate good from the intermediate-goods sector, and produces the final output by using factors such as human capital, labor, and capital. It can be seen that in this model, human capital, labor, capital, and technology are the production factors.

Based on Romer's endogenous growth model [17], the operating mechanism of the economic system is as follows. First, the research sector invests human capital and the existing knowledge stock to produce new knowledge. Then, the firms in the intermediategoods sector buy the new design from the intermediate-goods sector and use those designs to produce the intermediate goods. At last, a final goods sector purchases intermediate goods from the intermediate-good sector and invests labor, human capital, and intermediate goods in producing the final good.

In the endogenous growth model, Romer [17] used several simplifying assumptions. First, the population and the supply of labor are both constant. Second, the total stock of human capital in the population is fixed, and that the fraction supplied to the market is also fixed. Third, knowledge in an economy is composed of knowledge units. So the activity of the research sector in the economy can be elaborated as follows: the research 
sector transforms one knowledge unit into one new design type of intermediate goods and then sell this new design to the firm in the intermediate-goods sector. Fourth, once a firm in the intermediate-goods sector purchases a design for intermediate goods, it can obtain an infinitely lived patent on that design. Fifth, to simplify the analysis, Romer [17] assumed that the firm owning that patent on the design for intermediate good was the only one that would manufacture the intermediate-good. It means if this firm sells this intermediate-good to final-goods firms, since this firm is the only seller of this intermediategood, this firm will face a downward-sloping demand curve for its good, which indicates that this firm can set the monopoly price according to the demand of the final-good sector and obtains monopoly profits. Sixth, there are a large number of homogeneous households in the economy.

Based on Romer's endogenous growth model [17] and the existing literature, to explore the theoretical mechanism of driving green growth by innovation, we introduce energy consumption and environmental quality as production factors into Romer's model [17] and construct a green endogenous growth model. In addition, considering that innovation may decrease energy security risks by promoting clean energy production, we include the energy sector in the model. Suppose that an economy consists of four sectors which are the final-goods sector, the intermediate-goods sector, the R\&D sector, and the energy sector. There are five production factors in our model: capital, labor, energy consumption, environmental quality, and knowledge. Following the basic assumptions from Romer's [17], we assume that in homogeneous households, the supply of human capital is constant, and the firms in the intermediate-goods sector can obtain monopoly profits.

Before deriving the model, we need to elaborate on the rationality and appropriateness of our model.

Firstly, the rationality of our model can be presented in the following two perspectives. On the one hand, existing studies have proved that energy and environment can be included in the endogenous growth model as production factors. Moon and Sonn [26] noted that because energy was a kind of essential production factor that would not be represented by physical capital in the production process, so energy should be included in the production function as a separate production factor. Additionally, the rationality of incorporating the environment quality into production function is also proved by literature. Considine and Larson [27] illustrated that the government would supervise the pollution behavior of firms by environmental regulations such as pollution permits to control pollution. Governments create markets for pollution permits, while firms purchase the pollution permit from this market based on the principle of minimizing production costs. It indicates the external environmental cost of firms has been internalized as their production cost, so the environmental quality can also be included in the endogenous growth model as a production factor. On the other hand, it is reasonable for energy production to be included in the model as an economic sector. According to Wang [28], the increase in sectors in the model not only reflects economic development but also describes the economy more accurately. With the increasing external energy dependence, it is urgent to ensure energy security. Ensuring energy supply is the core of ensuring energy security. Consequently, to ensuring energy supply, more human capital and physical capital will be used to produce energy. In this way, the economy will gradually form an energy sector, which means it is reasonable to take energy production as an independent sector into the model.

Secondly, extensive researches have taken energy and environment as production factors into the endogenous growth model, which proves the appropriateness of our model. Wang [29] introduced energy and environment into the production function and constructed an endogenous growth model to explore the optimal sustainable growth path. Chen [30] constructed an endogenous economic growth model considering non-renewable energy and environmental pollution and revealed the optimal path of sustainable economic development. Additionally, there are some studies including the energy sector as the sector except for the final-goods sector, the intermediate-goods sector, and the R\&D sector [28]. 
To summarize, our model was rational and appropriate.

\subsection{Final-Goods Sector}

In the final-goods sector, manufacturers invest physical capital $K_{Y}$, human capital $L_{Y}$, energy $R$, and intermediate-goods to produce final goods. Additionally, the analysis above indicates that environmental quality $E$ can be included in the production function as a production factor. Therefore, the green output of the final-goods sector considering environmental quality and energy consumption can be expressed as:

$$
\begin{gathered}
Y=\left(K_{Y}^{\alpha} L_{Y}^{\beta} R^{\gamma} E^{\theta}\right)^{1-v} G^{v} \\
G=\left[\int_{0}^{A} A^{\eta} x(i)^{\sigma} d i\right]^{\frac{1}{\sigma}}
\end{gathered}
$$

where $Y$ represents final output, and $\alpha, \beta, \gamma$, and $\theta$ are the output elasticity of the four production factors respectively. Suppose that production of this sector is constant returns to scale and $\alpha+\beta+\gamma+\theta=1 . v$ is the output elasticity of intermediate-good. The subscript $Y$ of $K_{Y}$ and $L_{Y}$ indicates the final-goods sector. $x(i)$ is the quantity of the $i$-th intermediategood, $\mathrm{i} \in[0, A] . \sigma$ is the substitution elasticity between different kinds of intermediategood, and $\sigma<1$. A is the stock of knowledge. As mentioned above, knowledge in an economy is composed of knowledge units, so $A$ knowledge stock means $A$ knowledge units. The R\&D sector can transform $A$ knowledge units into $A$ types of intermediate goods. The intermediate-goods sector can improve the quality of intermediate goods by specialization. It can be seen that increasing types of intermediate-goods will not affect improving quality of a certain kind of intermediate-good, so "additive separability" (that is, the emergence of new products does not eliminate existing products) and "creative destruction" (that is, the production of high-quality intermediate-goods will completely replace low-quality ones) can be used in the same model under certain cases. According to Tao and Peng [18], we set $\eta$ as the intensity of improving the intermediate-goods quality by innovation and set $A^{\eta}$ as the quality of intermediate-goods improved by innovation.

According to equation (1), the profit function of the final-goods sector can be expressed as follows:

$$
\pi_{1}=Y-w L_{Y}-r K_{Y}-\int_{0}^{A} P(i) A^{\eta} x(i) d i-P_{R} R-P_{E} E
$$

where $w$ is the price of human capital (i.e., wage), $r$ is the price of physical capital (i.e., interest rate), $P(i)$ is the price of the $i$-th intermediate-goods, $P_{R}$ is the price of energy, and $P_{E}$ is the shadow price of environmental quality $\left(P_{E}\right.$ can be considered as the cost of improving environmental quality).

\subsection{Intermediate-Goods Sector}

Following the assumption of Romer [17], the firm in the intermediate-good can set the monopoly price $\bar{P}$ according to the demand of the final-good sector. To simply analysis, according to Tao and Peng [18], we assume that each intermediate-good firm needs one unit of capital to produce one unit of intermediate-good, and the cost of per unit capital is $c$, so the profit maximization decision of the $i$-th intermediate-good can be expressed as follows:

$$
\max _{x(i)} \pi_{2}(i)=P(i) A^{\eta} x(i)-c A^{\eta} x(i)
$$

\subsection{RED Sector}

Based on the existing stock of knowledge, the R\&D sector invests physical capital $K_{A}$ and human capital $L_{A}$ to produce a new design (knowledge). The aggregate stock of knowledge evolves according to:

$$
\dot{A}=\delta L_{A} K_{A} A
$$


Technological progress is one of the crucial factors affecting interest rates [31]. We assume that technological progress will affect the price of new designs by affecting the interest rate and Let $\bar{r}$ denote the interest rate affected by technological progress, and $\xi$ is the influence of technological progress on the interest rate, so $\bar{r}$ can be expressed as:

$$
\bar{r}=\xi A r
$$

\subsection{Energy Sector}

Following Tahvonen and Salo [32], we divided energy consumption into fossil energy consumption (such as coal, oil, and natural gas) and clean energy consumption (such as nuclear energy, wind energy, geothermal energy, and so on). Thus, we assume that $R=R_{F}+R_{C}$, where $R_{F}$ represents fossil energy consumption, and $R_{C}$ represents clean energy consumption. Suppose that $\iota$ is the proportion of clean energy consumption in total energy consumption, so $R_{C}=\imath R$. According to Xiao and Tang [33], we assumed that energy consumption is equivalent to energy production, so the energy sector can be divided into the fossil energy sector and the clean energy sector. Among them, fossil energy production depends on resource exploitation, while clean energy production depends on technological input [34]. Suppose that the energy supply is $S$, and the growth rate of fossil-energy recoverable reserves is $\mu$, and the proportion of fossil energy production in primary energy production is $\kappa$. According to Yan and Zhang [34], we assumed that the clean energy production grows at the rate $j$, and set $\varphi$ as the proportion of clean energy production in primary energy production. Then energy supply $S$ evolves according to the following equation:

$$
\dot{S}=(\mu \kappa+j \varphi) S-R
$$

\subsection{Environmental Constraints}

Suppose that the environmental quality $E$ is affected by the following two aspects. For one thing, the self-purification ability of the environment can reduce pollution and improve the environmental quality [35]. For another, energy consumption and technological progress will also affect the environmental quality. According to Zhang and Zuo [36] and Wang et al. [37], environmental quality $E$ evolves according to the following equation:

$$
\dot{E}=b E+A^{\zeta} \tau \omega(1-\iota) R
$$

where $\dot{E}$ denotes the increment of environmental quality, $b$ denotes the self-purification rate of the environment, $\zeta$ denotes the impact of technological progress on environmental quality, $\tau$ indicates the proportion of fossil energy in energy consumption, and $\omega$ indicates the pollutant emission coefficient of fossil energy consumption.

\subsection{Households}

According to Barro [38], in the economy, households provide labor in exchange for wages, obtain interest income from resources, purchase products for consumption, and save by accumulating additional assets. Because the household will make optimal decisions according to the principle of utility maximization and thereby affect the equilibrium state of the economy, a complete endogenous growth model needs to consider the household. Suppose that the utility function of homogeneous households is $U=\ln C$, and each household pursues utility maximization. Then the optimal program of the representative household could be expressed as follows:

$$
\begin{gathered}
\max \int_{0}^{+\infty} \ln C e^{-\rho t} d t \\
\text { s.t. } \dot{K}=r K+w L-C \\
\dot{A}=\delta K_{A} L_{A} A
\end{gathered}
$$




$$
\begin{gathered}
\dot{S}=(\mu \kappa+j \varphi) S-R \\
\dot{E}=b E+A^{\zeta} \tau \omega(1-\iota) R \\
L=L_{A}+L_{Y}
\end{gathered}
$$

where $\rho$ is the discount rate, $C$ is household consumption, $K$ is total physical capital, and $L$ is total human capital. Suppose that the representative household gets income from investment and labor and spends part of its income on consumption. The budget constraint equation is illustrated in equation (9). According to the above constraints, we constructed the following current-valued Hamiltonian function:

$$
H=\ln C+\lambda_{1}(r K+w L-C)+\lambda_{2} \delta L_{A} A+\lambda_{3}[(\mu \kappa+j \varphi) S-R]+\lambda_{4}\left[b E+A^{\zeta} \tau \omega(1-\iota) R\right]
$$

where $\lambda_{1}, \lambda_{2}, \lambda_{3}$, and $\lambda_{4}$ are the shadow prices of physical capital, energy, environment, and technology at time $t$ respectively. The state variables are $K, A, S$, and $E$, and the control variables are $C, R, L, L_{Y}, L_{A}$, and $K_{A}$.

Four Euler conditions could be obtained by deriving the state variables $K, A, S$, and $E$ :

$$
\begin{gathered}
\frac{\partial H}{\partial K}=\lambda_{1} r=\rho \lambda_{1}-\dot{\lambda}_{1} \\
\frac{\partial H}{\partial A}=\lambda_{2} \delta K_{A} L_{A}+\lambda_{3} K_{R N}+\zeta \lambda_{4} A^{\zeta-1} \tau \omega(1-\iota) R=\rho \lambda_{2}-\dot{\lambda}_{2} \\
\frac{\partial H}{\partial S}=\lambda_{3}(\mu \kappa+j \varphi)=\rho \lambda_{3}-\dot{\lambda}_{3} \\
\frac{\partial H}{\partial E}=\lambda_{3} b=\rho \lambda_{4}-\dot{\lambda}_{4}
\end{gathered}
$$

Then the following six optimal first-order conditions are obtained by deriving the control variables $C, R, L_{,} L_{Y}, L_{A}$, and $K_{A}$ :

$$
\begin{gathered}
\frac{\partial H}{\partial C}=\frac{1}{C}-\lambda_{1}=0 \\
\frac{\partial H}{\partial R}=-\lambda_{3}(1-\iota)+\lambda_{4} A^{\zeta} \tau \omega(1-\iota)=0 \\
\frac{\partial H}{\partial L}=0 \\
\frac{\partial H}{\partial L_{Y}}=0 \\
\frac{\partial H}{\partial L_{A}}=0 \\
\frac{\partial H}{\partial K_{A}}=0
\end{gathered}
$$

\subsection{Equilibrium}

Along the balanced growth path, variables $C, K, A$, and $Y$ grow at the rate $g$, that is, $g_{C}=g_{K}=g_{A}=g_{Y}=g$. The return rates of human capital and physical capital in the final-goods sector and the R\&D sector are equal on this path. Then using Equations (8) and (10)-(15) to replace the coefficients from the human capital price $w$ and the physical capital price $r$, we can obtain the following expressions of $L_{Y}$ and $L_{A}$.

$$
L_{Y}=\frac{\beta \xi \nu \zeta}{\beta \xi \nu \zeta+b-\mu \kappa-j \varphi} L
$$




$$
L_{A}=\frac{b-\mu \kappa-j \varphi}{\beta \xi \nu \zeta+b-\mu \kappa-j \varphi} L
$$

In accordance with Equations (1)-(3) and (12)-(15), the production function of the final-goods sector can be presented as follows: The derivation of Equation (18) is presented in Appendix A.

$$
Y=K_{Y}^{\alpha} L_{Y}^{\beta} R^{\gamma} E^{\theta}\left(\frac{\zeta \nu^{2}}{\rho \zeta+b-\mu \kappa+j \varphi}\right)^{\frac{v}{1-v}} A^{\frac{v(1-\sigma)(\eta+1)}{\sigma(1-\nu)}}
$$

We adopted the Solow residual method to measure the innovation-driven effect of green growth. Suppose that an economy is driven by innovation, human capital, physical capital, energy, and the environment. We define $E_{A}, E_{L}, E_{K}, E_{R}$, and $E_{E}$ as the driven effects of these five factors on green growth, respectively, and assume that $E_{A}+E_{L}+$ $E_{K}+E_{R}+E_{E}=1$. According to the Solow residual method, $E_{A}$ can be illustrated as:

$$
E_{A}=1-E_{K}-E_{L}-E_{R}-E_{E}=1-\left[\frac{L_{Y}}{L_{A}} \times \frac{(b-\mu \kappa-j \varphi) v}{(\rho \zeta+b-\mu \kappa-j \varphi) \beta \xi}\right]^{\frac{v}{1-\nu}}
$$

As demonstrated in Equation (19), the innovation-driven effect of green growth is the result of multiple factors in an economy. This effect is related to the human capital allocation proportion $L_{Y} / L_{A}$, the output elasticity of human capital $\beta$, the output elasticity of intermediate-goods $v$, the proportion of fossil-energy and clean-energy production in primary energy production (corresponding to the parameter $\kappa$ and $\varphi$ ), the growth rate of clean energy production $j$, the discount rate $\rho$, the environmental self-purification rate $b$, the growth rate of fossil-energy recoverable reserves $\mu$, the impact of technological progress on environmental quality $\zeta$, and the impact of technology on interest rates $\xi$. The first six parameters will be determined by calculation, and the last five parameters will be determined by the calibration method.

\subsection{Industry Classification and Parameter Estimation \\ 2.8.1. Industrial Classification}

The National Bureau of Statistics adjusted the industrial classification standards in 2011. As a result, there are inconsistent classification standards in the industry data from 2005-2016, so it is essential to reclassify the industry. As Table 1 implies, referring to the Industry Classification Standard of Economy (GB/t 4754-2017) [39], we grouped industries

\begin{tabular}{|c|c|c|c|c|c|}
\hline Code & Industry & Code & Industry & Code & Industry \\
\hline I1 & Primary industry & I15 & Manufacture of furniture & I29 & $\begin{array}{l}\text { Manufacture of } \\
\text { general-purpose } \\
\text { machinery }\end{array}$ \\
\hline $\mathrm{I} 2$ & $\begin{array}{l}\text { Mining and washing of } \\
\text { coal }\end{array}$ & I16 & $\begin{array}{l}\text { Manufacture of paper and } \\
\text { paper products }\end{array}$ & $\mathrm{I} 30$ & $\begin{array}{l}\text { Manufacture of } \\
\text { special-purpose } \\
\text { machinery }\end{array}$ \\
\hline I3 & $\begin{array}{l}\text { Extraction of petroleum } \\
\text { and natural gas }\end{array}$ & I17 & $\begin{array}{l}\text { Printing, reproduction of } \\
\text { recording media }\end{array}$ & I31 & $\begin{array}{c}\text { Manufacture of transport } \\
\text { equipment }\end{array}$ \\
\hline $\mathrm{I} 4$ & $\begin{array}{l}\text { Mining and processing of } \\
\text { ferrous metal ores }\end{array}$ & I18 & $\begin{array}{l}\text { Manufacture of articles for } \\
\text { culture, education and } \\
\text { sport activity }\end{array}$ & $\mathrm{I} 32$ & $\begin{array}{l}\text { Manufacture of electrical } \\
\text { machinery and equipment }\end{array}$ \\
\hline I5 & $\begin{array}{l}\text { Mining and processing of } \\
\text { non-ferrous metal ores }\end{array}$ & I19 & $\begin{array}{l}\text { Processing of petroleum, } \\
\text { coking, and nuclear fuel }\end{array}$ & I33 & $\begin{array}{l}\text { Manufacture of } \\
\text { communication } \\
\text { equipment, computers }\end{array}$ \\
\hline I6 & $\begin{array}{l}\text { Mining and processing of } \\
\text { nonmetal ores }\end{array}$ & $\mathrm{I} 20$ & $\begin{array}{l}\text { Manufacture of raw } \\
\text { chemical materials and } \\
\text { chemical products }\end{array}$ & $\mathrm{I} 34$ & $\begin{array}{c}\text { Manufacture of measuring } \\
\text { instruments and } \\
\text { machinery }\end{array}$ \\
\hline
\end{tabular}
into 40 subdivided industries.

Table 1. Industrial classification. 
Table 1. Cont

\begin{tabular}{|c|c|c|c|c|c|}
\hline Code & Industry & Code & Industry & Code & Industry \\
\hline I7 & $\begin{array}{l}\text { Processing of food from } \\
\text { agricultural products }\end{array}$ & $\mathrm{I} 21$ & Manufacture of medicines & I35 & $\begin{array}{c}\text { Production and } \\
\text { distribution of electric } \\
\text { power }\end{array}$ \\
\hline I8 & Manufacture of foods & $\mathrm{I} 22$ & $\begin{array}{l}\text { Manufacture of chemical } \\
\text { fibers }\end{array}$ & $\mathrm{I} 36$ & $\begin{array}{l}\text { Production and } \\
\text { distribution of gas }\end{array}$ \\
\hline I9 & Manufacture of beverages & $\mathrm{I} 23$ & Manufacture of rubber & I37 & $\begin{array}{c}\text { Production and } \\
\text { distribution of water }\end{array}$ \\
\hline $\mathrm{I} 10$ & Manufacture of tobacco & $\mathrm{I} 24$ & $\begin{array}{l}\text { Manufacture of plastics } \\
\text { Manufacture of }\end{array}$ & I38 & Other industrial sectors \\
\hline I11 & Manufacture of textile & $\mathrm{I} 25$ & $\begin{array}{l}\text { non-metallic mineral } \\
\text { products }\end{array}$ & I39 & Construction \\
\hline $\mathrm{I} 12$ & $\begin{array}{c}\text { Manufacture of textile } \\
\text { wearing apparel, footwear, } \\
\text { and caps }\end{array}$ & $\mathrm{I} 26$ & $\begin{array}{l}\text { Smelting and pressing of } \\
\text { ferrous metals }\end{array}$ & $\mathrm{I} 40$ & Tertiary industry \\
\hline I13 & $\begin{array}{c}\text { Manufacture of leather, } \\
\text { fur, feather, and related } \\
\text { products }\end{array}$ & $\mathrm{I} 27$ & $\begin{array}{l}\text { Smelting and pressing of } \\
\text { non-ferrous metals }\end{array}$ & & \\
\hline I14 & $\begin{array}{l}\text { Processing of timber, } \\
\text { manufacture of wood, } \\
\text { and related products }\end{array}$ & $\mathrm{I} 28$ & $\begin{array}{l}\text { Manufacture of metal } \\
\text { products }\end{array}$ & & \\
\hline
\end{tabular}

2.8.2. Measurement of Output Elasticity of Human Capital and Intermediate-goods

To measure the output elasticity of human capital and intermediate-goods, we constructed an econometric model as follows:

$$
\ln \left(V a l_{i}\right)=c_{i}+\beta_{1 i} \ln \left(C a p_{i}\right)+\beta_{2 i} \ln \left(L a b_{i}\right)+\beta_{3 i} \ln \left(I n t_{i}\right)+\beta_{4 i} \ln \left(E n e_{i}\right)+\beta_{5 i} \ln (E n v)+\varepsilon_{i}
$$

where $c_{i}$ is a constant term, $\operatorname{Val}_{i}, \mathrm{Cap}_{i}, \mathrm{Lab} b_{i}, \mathrm{Int}_{i}$, and $E n e_{i}$ represent the added value, physical capital input, human capital input, intermediate-goods input, and energy input of the $i$-th industry respectively, and Env represents the same environmental quality in all industries. The coefficient $\beta_{1 i}, \beta_{2 i}, \beta_{3 i}, \beta_{4 i}$, and $\beta_{5 i}$ represent the output elasticity of each variable respectively. $\varepsilon_{i}$ is a random error. The value-added data came from the China Industrial Statistical Yearbook. To eliminate the influence of price changes, we used the producer's factory price index to reduce the output value of the current year's price and obtain the sub-sector output data based on 1990. The physical capital input of industries was calculated by the perpetual inventory method. Human capital data of industries were from the results in the previous section. The data of intermediate-goods input of industries came from the CIP 3.0 database, and we deflated the intermediate inputs using the method of Chen [40]. The energy input was measured by the energy consumption, and the data is from the China Energy Statistical Yearbook. Environmental quality was measured by the China Environmental Quality Index, which is from the Annual Report of China Environmental Quality Comprehensive Evaluation in China. In the above six variables, except for added value, the energy input, intermediate-goods input, and China Environmental Quality Index were collected from the literature, databases, and yearbooks, data of physical capital input and human capital input were obtained from calculations (see Appendix B for the calculation method). The descriptive statistics of the variables involved in this section are presented in Table 2. It can be seen that the added value had an average of standard deviations of 7.4160 with a standard deviation of 1.3742 , which indicates the distinct differences of the added value in different industries. The standard deviation and the median value of physical capital input, human capital input, intermediate-goods input were relatively close, which demonstrates the overall situation of these three types of data was relatively stable. Compare with other variables, the average value of energy input was lower, at 3.2968, and the standard deviation was higher, at 1.4468, indicating that energy input had more significant industry differences. Furthermore, the environmental quality index had an 
average of 4.4842 with a standard deviation of 0.1863 , which means the fluctuating degree of the environmental quality index was relatively low.

Table 2. Descriptive statistics of variables.

\begin{tabular}{|c|c|c|c|c|c|c|c|}
\hline Variables & Definition & Observations & Mean & S.D. & Min. & Median & Max. \\
\hline $\ln \mathrm{Val}_{i}$ & The ratio of added value & 480 & 7.4160 & 1.3742 & 11.0138 & 7.4413 & 3.5336 \\
\hline $\operatorname{lnCap} i$ & The ratio of physical capital input & 480 & 7.6358 & 1.2682 & 12.8096 & 7.5076 & 4.4773 \\
\hline $\ln L a b_{i}$ & The ratio of human capital input & 480 & 7.8935 & 1.3393 & 12.6386 & 7.7740 & 4.9176 \\
\hline $\ln \operatorname{In} t_{i}$ & The ratio of intermediate-goods input & 480 & 7.9532 & 1.3747 & 11.7719 & 7.8966 & 4.2857 \\
\hline $\ln E_{n} e_{i}$ & The ratio of energy input & 480 & 3.2968 & 1.4468 & 6.6177 & 3.0350 & 0.3468 \\
\hline $\ln E n v$ & The ratio of environmental quality & 480 & 4.4842 & 0.1863 & 4.8885 & 4.4362 & 4.3061 \\
\hline
\end{tabular}

\subsubsection{Calculation of Human Capital Allocation Proportion $\mathrm{L}_{Y} / \mathrm{L}_{\mathrm{A}}$}

Referring to the accounting method of Fan et al. [41], we calculate the total human capital. $L_{A}$ equals the number of employees with a college degree or above multiplied by its weight in the total human capital, and $L_{Y}$ is the remaining human capital after subtracting $L_{A}$ from the total human capital. The ratio of $L_{Y}$ to $L_{A}$ is the human capital allocation proportion. Given the lower proportion of employees with a college degree or above in the primary industry, we relaxed the education level of $L_{A}$ in the primary industry to senior high school. The related data comes from the China Statistics Yearbook, China Tertiary Industry Statistics Yearbook, China Labor Statistics Yearbook, China Economic Census Yearbook 2008, and the China Stock Market \& Accounting Research (CSMAR) database. Measurement results are in Appendix C.

\subsubsection{Calculation of Parameter $\kappa$, Parameter $\varphi$ and Parameter j}

According to the data from China Energy Statistical Yearbook, we could obtain the proportion of fossil-energy production and the proportion of clean energy production in primary energy production (corresponding to the parameter $\mathcal{K}$ and $\varphi$ ), where the parameter $\mathcal{K}$ is measured by the proportion of fossil energy, the parameter $\varphi$ is measured by the proportion of electric power and other energy production. Additionally, we estimated the growth rate of clean energy production with the growth rate of electricity and other energy production. Measurement results are shown in Table 3.

Table 3. Measurement results.

\begin{tabular}{ccccccccccccc}
\hline Parameters & $\mathbf{2 0 0 5}$ & $\mathbf{2 0 0 6}$ & $\mathbf{2 0 0 7}$ & $\mathbf{2 0 0 8}$ & $\mathbf{2 0 0 9}$ & $\mathbf{2 0 1 0}$ & $\mathbf{2 0 1 1}$ & $\mathbf{2 0 1 2}$ & $\mathbf{2 0 1 3}$ & $\mathbf{2 0 1 4}$ & $\mathbf{2 0 1 5}$ & $\mathbf{2 0 1 6}$ \\
\hline Parameter $\kappa$ & 0.961 & 0.960 & 0.959 & 0.954 & 0.952 & 0.948 & 0.952 & 0.944 & 0.940 & 0.932 & 0.927 & 0.914 \\
Parameter $\varphi$ & 0.039 & 0.040 & 0.041 & 0.046 & 0.048 & 0.052 & 0.048 & 0.056 & 0.060 & 0.068 & 0.073 & 0.086 \\
Parameter $j$ & 0.112 & 0.096 & 0.106 & 0.172 & 0.076 & 0.178 & 0.011 & 0.193 & 0.092 & 0.132 & 0.065 & 0.113 \\
\hline
\end{tabular}

\subsubsection{Other Parameter Calibration}

As presented in Table 4, based on the relevant research literature, we calibrated the values of the other five parameters in Equation (19).

Table 4. Parameter calibration.

\begin{tabular}{ccc}
\hline Parameter Name & Parameter Symbol & Value \\
\hline The impact of technological progress on interest rate & $\xi$ & 0.4880 \\
The impact of technological progress on environmental quality & $\zeta$ & 0.4430 \\
Growth rate of recoverable energy reserves & $\mu$ & 0.0018 \\
Self-purification speed of environment & $b$ & 0.0215 \\
Discount rate & $\rho$ & 0.9740 \\
\hline
\end{tabular}


According to the results of Yao et al. [42], the impact coefficient of technological progress on China's natural interest rate change was 0.488 . We used this data to represent the parameter $\xi$. In regards to the impact of technological progress on environmental quality, most studies choose carbon emissions or wastewater emissions as environmental indicators [43,44], while Jiang and Liu [45] studied by constructing the environmental quality index and found that the impact coefficient of technological progress on environmental quality was 0.443 . Therefore, we selected this data to represent the parameter $\zeta$. We measured the growth rate of recoverable energy reserves by that of proved energy reserves. Given that the data of proved developed reserves fluctuate wildly, we calculated its average growth rate from 2004 to 2017to represent the growth rate of recoverable energy reserves. By calculation, we found that the average growth rate of proved developed reserves was 0.0018 , so we use this data to represent the parameter $\mu$. The related data came from the China National Petroleum Corporation Yearbook. Following Petschel-held et al. [29], we set the environmental self-purification rate as 0.0215 . Finally, referring to the calculation method of Huang [46], we determined the discount rate $\rho$ to be 0.974 .

\subsubsection{Measurement of Innovation-Driven Effect of Green Growth}

Based on the above parameters and Equation (19), we measure the innovation-driven effect of green growth in 40 industries, and the results are presented in Figure 1. It can be seen that from 2005 to 2016, the innovation driven-effect of green growth increased from 0.2729 to 0.3446 , which was an increase of $26.3 \%$ in 12 years.

To keep the analysis simple, according to whether the innovation-driven effect is higher than the average, we classified 40 industries into two categories: the first category was the industries with the higher innovation-driven effect, while the second category was the industries with the lower innovation-driven effect. As presented in Figure 1, the effects of innovation on green growth for the industries in two categories were different. On the one hand, industries in the first category were distributed in capital-intensive industries such as electrical manufacturing and power production and supply, while the industries in the second category were distributed in labor-intensive industries such as primary industry, the clothing industry, and textile manufacturing. On the other hand, the average growth rate of industries in the first category is lower than that of industries in the second category. The results report that the average growth rate of industries in the first category is $3.04 \%$, where the industry with the highest growth rate is the coal mining, and washing where the growth rate reached $4.76 \%$, and the industry with the lowest growth rate was gas production and distribution with a growth rate reaching $1.74 \%$. The industry in the second category also has an average growth rate of $5.00 \%$, where the industry with the highest growth rate is nonmetal ores mining and processing with a growth rate of $11.59 \%$, and the industry with the lowest growth rate is petroleum, coking and nuclear fuel processing with a growth rate of $2.32 \%$. This may be because that most industries in the first category have higher technology levels; it is more difficult for these industries to drive green growth through innovation. Thus, the growth rates for these industries were lower than those for industries in the second category. 


\section{Innovation-driven effect}

Industries with low innovation-driven effect Industries with high innovation-driven effect

$$
\text { I39 }
$$

I18$$
\text { I7 }
$$

I25

I12

I11

I1

$\mathrm{I} 16$

$\mathrm{I} 14$

I8

I15

I13
I23

I19

I17

I6
I30

I15

$\mathrm{I} 4$
$\mathrm{I} 20$

I 20
I9

I2

I28

I24

I22

I22
I29

I21

I32

I27

I10

I36

I37

I31

I35

$\mathrm{I} 33$
$\mathrm{I} 34$

I3

I40

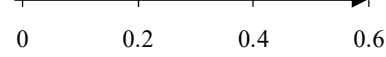

(a) Measurement results
Innovation-driven effect

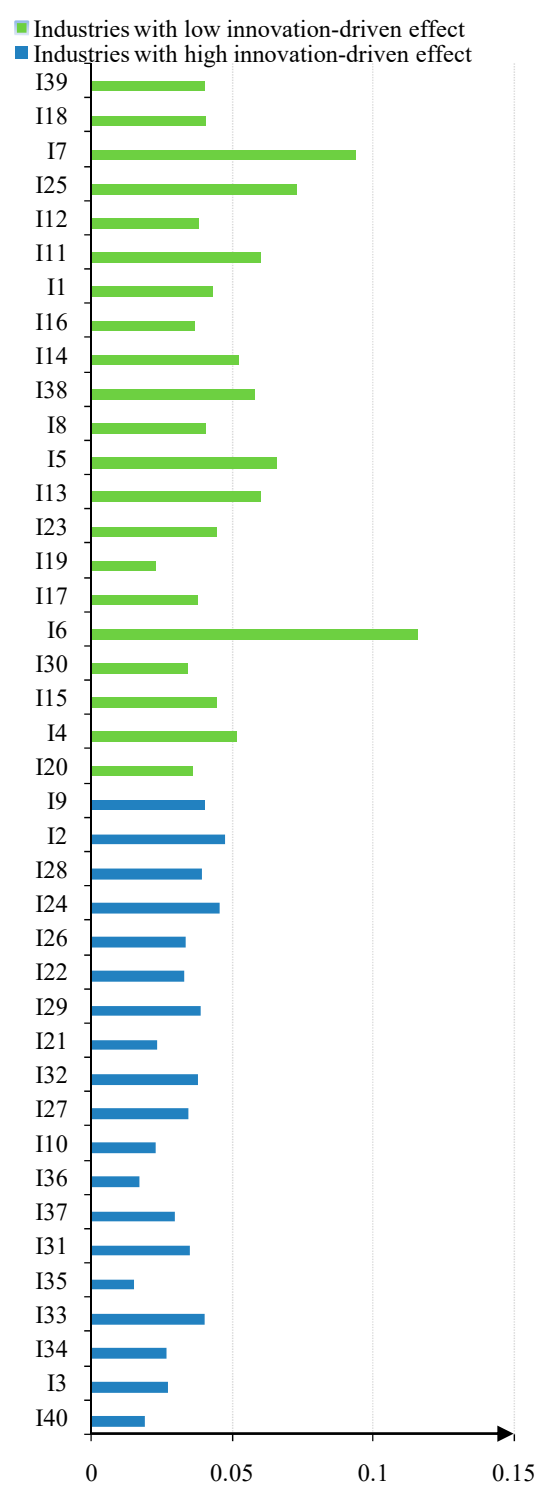

(b) Growth rate

Figure 1. Measurement results of innovation driven-effect for 40 industries from 2005 to 2016. (a) Measurement results; (b) Growth rate.

\section{Measurement and Analysis of Green Added Value}

The classic model of accounting for the green growth level is the SEEA proposed by the United Nations in 1993. Besides the SEEA, other institutions accounted for the green growth by constructing the indicator system [22]. These indicators included in these systems involve not only environmental pollution and resource depletion but also involve national status, life quality, and social development, which reflect the country's green growth comprehensively. Nevertheless, the indicator selections of these indicator systems are highly subjective, and the accounting methods are complex. Consequently, more studies choose to measure green growth based on the SEEA [47]. To sum up, we also select the SEEA to calculate the green added value

\subsection{Calculation of Green Added Value}

Based on the SEEA, the accounting equation of green added value can be expressed as:

$$
G A V=T A V-(E P C+R D C)
$$


where $G A V$ denotes green added value, TAC denotes the traditionally added value, EPC denotes the environmental pollution cost, and $R D C$ denotes resource depletion cost. The environmental pollution cost refers to the environmental pollution and protection cost, and resource depletion cost refers to the consumption of the natural resources in the economy. The procedures to measure green added value are as follows: (1) calculate the environmental pollution cost and resource depletion cost; (2) subtract the two costs from the traditionally added value, obtain the green added value; (3) use the GDP deflator to deflate green added value to 1990 constant prices. The data of the traditionally added value adopts the data in the third part. The environmental pollution cost and the resource depletion cost were calculated as follows.

\subsubsection{Measurement of Environmental Pollution Cost}

To simplify analysis, some studies only select the $\mathrm{CO}_{2}$ emissions to measure the environmental pollution cost. To calculate more accurately, in addition to $\mathrm{CO}_{2}$ emissions, we also include $\mathrm{SO}_{2}$ emissions and wastewater discharges into the accounting of the environmental pollution cost. Among them, the $\mathrm{CO}_{2}$ pollution cost is expressed as the product of $\mathrm{CO}_{2}$ emissions and its shadow price. The procedures to measure $\mathrm{CO}_{2}$ pollution cost are as follows: Firstly, based on Guidelines for Accounting Methods and Reporting of Greenhouse Gas Emissions of China's Power Generation Enterprises (Trial), we measured the $\mathrm{CO}_{2}$ emissions generated by coal, natural gas, petroleum, and other fossil fuels in industries. Secondly, we selected the shadow price calculated by the Japanese environmental impact assessment method LIME2 [47] as the shadow price of $\mathrm{CO}_{2}$ emissions and adjust this price according to purchasing power parity. Thirdly, we multiplied the $\mathrm{CO}_{2}$ emissions with its shadow price to gain the $\mathrm{CO}_{2}$ emission pollution cost.

We took the product of $\mathrm{SO}_{2}$ emission and its shadow price as the $\mathrm{SO}_{2}$ pollution cost and took the product of wastewater discharge and wastewater treatment price as the wastewater pollution cost. The data of $\mathrm{SO}_{2}$ emissions and wastewater discharge comes from the China Environmental Statistical Yearbook, China Tertiary Industry Statistical Yearbook, and the China Statistical Yearbook. The shadow price of $\mathrm{SO}_{2}$ was selected from the results of Zeng et al. [48]. The price of wastewater treatment comes from the China Price Yearbook.

\subsubsection{Measurement of Resource Depletion Cost}

We measured resource depletion costs by the product of energy consumption and the shadow price of fossil energy. The data of energy consumption originates from the China Energy Statistical Yearbook. The shadow price of fossil energy comes from the results of Xie and $\mathrm{Yu}[49]$.

\subsection{Measurement of Green Added Value}

As presented in Figure 2, the proportion of the green added value in the traditionally added value increased from $79.54 \%$ in 2005 to $92.25 \%$ in 2016, which indicates that China's economic development mode has been optimized. Besides, with the implementation of environmental policies, the environmental cost was reduced year by year. This reduction in cost ultimately made the average growth rate $(14.46 \%)$ of green added value higher than that of the traditionally added value $(12.81 \%)$.

To illustrate the impact of the natural environment on green growth, based on the calculation results, we further analyze the changes in environmental pollution cost and resource depletion cost from 2005 to 2016. It can be seen from the results that, on the one hand, green growth was more affected by environmental pollution cost: the average proportion of environmental pollution cost in the total environmental cost is $89.61 \%$, while resource depletion cost only accounts for $10.39 \%$. This presents that controlling the cost of environmental pollution was the key to promote green growth. However, it is worth noting that as time goes on, the proportion of environmental pollution cost decreased from $89.89 \%$ in 2005 to $83.33 \%$ in 2016 , while the proportion of resource depletion cost increased from $10.11 \%$ in 2005 to $16.67 \%$ in 2016 . This result indicates that China's green 
growth is driven by the decline of environmental pollution costs. On the other hand, as far as the cost of environmental pollution is concerned, carbon emissions pollution cost was the main component of this cost. The calculation results present that carbon emissions pollution cost accounts for $57.55 \%$ of the environmental pollution cost while the cost of wastewater pollution and $\mathrm{SO}_{2}$ pollution only accounted for $27.92 \%$ and $14.53 \%$, respectively. Same as the environmental pollution cost, the proportion of carbon emissions pollution cost declined from $57.39 \%$ in 2005 to $55.63 \%$ in 2016 , which means that the decline of the environmental pollution cost is mainly caused by the reduction in carbon emissions. The above analysis demonstrates that China's green growth mainly benefits from the control of environmental pollution, especially the control of carbon emissions.

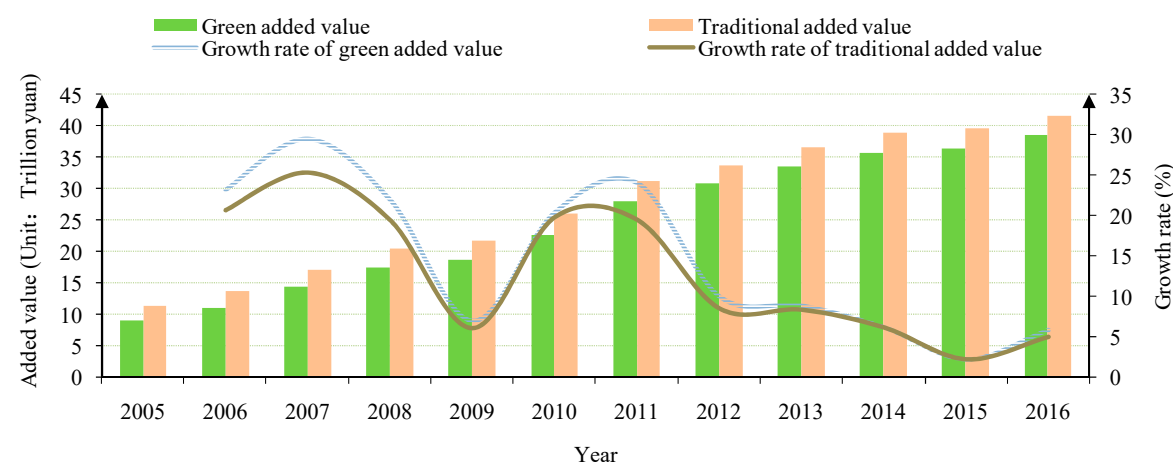

Figure 2. Measurement results of innovation driven-effect for 40 industries from 2005 to 2016.

To explore the industrial disparities of green added value, we classified 40 industries into two categories based on the proportion of green added value in the traditionally added value: one contains the industries with lower than the average proportion (we also call these as the industries with a lower level of green growth), and the other contains the industries with higher than the average proportion (we also call these as the industries with a higher level of green growth). As illustrated in Figure 3, the growth rate of green added value for the industries in the first category $(18.26 \%)$ is higher than that in the second category $(14.51 \%)$. This is because the higher the levels of green growth, the less space for abatement, so the average growth rate of industries in the first category is lower than that in the second category. In the first category, electric power production and distribution was the industry with the highest average growth rate at $35.85 \%$, while chemical fiber manufacturing was the industry with the lowest average growth rate at $12.48 \%$. Nonmetal ores mining and processing was the industry with the highest growth rate at $22.07 \%$ in the second category, while tobacco manufacturing was the industry with the lowest growth rate at $9.82 \%$.

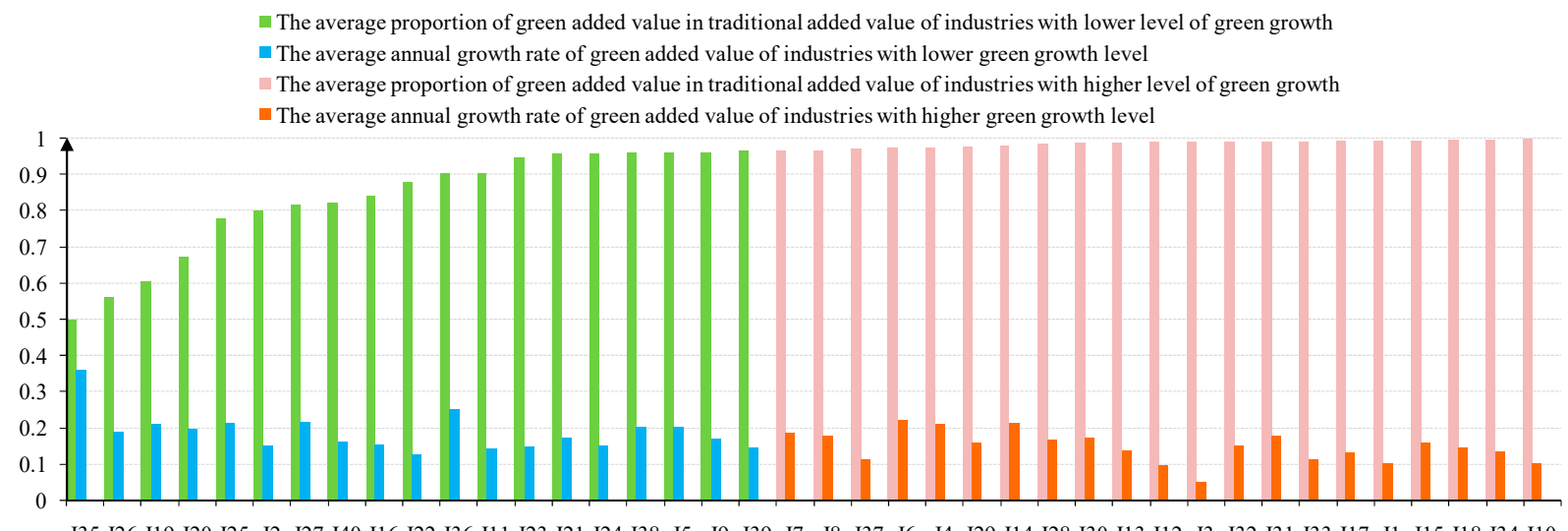

Figure 3. Measurement results of green added value for 40 industries from 2005 to 2016. 


\section{The Mechanism of Driving Green Growth and Decreasing Energy Security Risks by Innovation}

Based on the different industrial characteristics, each industry faces divergent abatement pressures and energy security risks. Thus, we expect that the mechanism of driving green growth and decreasing energy security risk by innovation also has industry disparities, and there may be nonlinear characteristics for the relationship between innovation and green growth and between innovation and energy security risks.

The traditional method to explore these nonlinear characteristics is to set a division standard (that is, threshold) subjectively by researchers, then divide the sample into several parts according to the division standard and carry out piecewise regression. However, this traditional method needs to set the threshold subjectively, which means that this method can neither estimate the threshold parameters nor test the significance of the threshold statistically, so it lacks reliability [50]. Hansen [51] proposed the threshold regression model in 1999. This model overcomes the limitations of traditional methods: On the one hand, this model does not need to assume the form of a nonlinear equation, and the threshold value and number are determined by the sample data endogenously, which overcomes the influence of subjectivity. On the other hand, this model estimates the threshold parameters through statistical inference and adopts the bootstrap method to test the significance of the threshold. So, this model is frequently used to explore the nonlinear influence of a variable on other variables [52]. As noted above, we selected a threshold regression model to examine the mechanism of driving green growth and decreasing energy security risks by innovation.

\subsection{The Mechanism of Driving Green Growth by Innovation}

\subsubsection{Model}

According to Hansen [51], we constructed the following threshold regression model:

$$
\ln \left(\operatorname{Val}_{i t}\right)=\beta_{1} \ln \left(I E_{i t}\right) I\left(I E_{i t} \leq \gamma_{1}\right)+\beta_{2} \ln \left(I E_{i t}\right) I\left(I E_{i t}>\gamma_{1}\right)+\beta_{3} X_{i t}+\mu_{i}+\varepsilon_{i t}
$$

In Equation (22), $V_{a l}$ it is green added value, $I E_{i t}$ is the innovation driven-effect of green growth; coefficients $\beta_{1}, \beta_{2}$, and $\beta_{3}$ are the output elasticity of variables. Subscripts $i$ and $t$ denote different industries and years; $I\left(I E_{i t} \leq \gamma_{1}\right)$. and $I\left(I E_{i t}>\gamma_{1}\right)$ denote the indicator functions. If the expression is true, the value of I is equal to 1 or otherwise $0 \gamma_{1}$ denotes threshold parameter; $X_{i t}$ represents control variables, $u_{i}$ represents individual fixed effect; $\varepsilon_{i t}$ represents the stochastic error.

\subsubsection{Variable Selection and Data Sources}

We selected the innovation driven-effect of green growth as the threshold variable. Referring to the related literature on green growth, we selected physical capital input (denoted as Cap), labor input (denoted as Lab), energy intensity (denoted as Energy), environmental regulation (denoted as Environment), and marketization (denoted as Market) as the control variables. Specifically, labor input was represented by the human capital input of the final-goods sector, and energy intensity is denoted by the ratio of energy consumption to added value. The environmental regulation was represented by the ratio of the pollution treatment cost to the added value, where the pollution treatment cost includes the wastewater and waste gas treatment costs. Marketization was denoted by the ratio of the added value of private and individual enterprises to total added value. The data of the added value for private and individual enterprises and pollution treatment cost came from the China Environmental Statistical Yearbook, the China Tertiary Industry Statistical Yearbook, the China Industrial Statistical Yearbook, and the China Statistical Yearbook. Other data came from the third part.

\subsubsection{Regression Results for the Entire Industry}

Before regression, we needed to test the threshold effect. As noted in Table 5, the results of the double threshold and triple threshold were not significant, while the results of the 
single threshold were significant at the $1 \%$ level. Therefore, we determined the model as a single threshold model, the threshold was 0.2915 , and the corresponding $95 \%$ confidence interval was $0.2890-0.2922$.

Table 5. Results for threshold effect test of the entire industry.

\begin{tabular}{ccccccc}
\hline Test Type & Threshold Parameter & Confidence Interval & RSS & MSE & F Statistic & $p$-Value \\
\hline Single threshold & 0.2915 & $0.2890-0.2922$ & 14.9340 & 0.0319 & 28.25 & 0.0380 \\
Double threshold & 0.4107 & $0.4090-0.4114$ & 14.6790 & 0.0314 & 8.13 & 0.7917 \\
Triple threshold & 0.4119 & $0.4098-0.4154$ & 14.3095 & 0.0307 & 12.08 & 0.4033 \\
\hline
\end{tabular}

The threshold value, threshold interval, $p$-value, and critical value of each threshold effect were obtained by repeated sampling 500 times with the bootstrap method, the same below.

To present the test results, we used the likelihood ratio (LR) statistics to plot the thresholds and their confidence intervals. As presented in Figure 4, the LR statistic corresponding to the first threshold is far less than the critical value of 7.35. This image indicates that the single threshold estimation was authentic. In comparison, most curves of the second threshold were below the dotted line, and there were multiple estimates of the third threshold. Combined with the test results in Table 5, we could determine the model as a single threshold model.

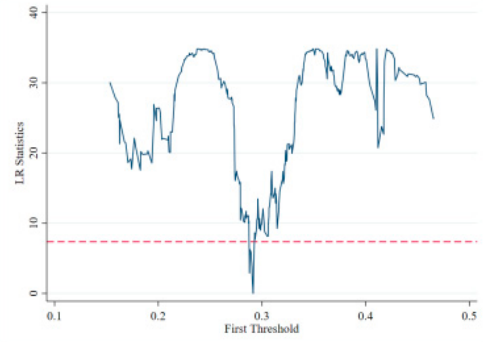

(a) First threshold

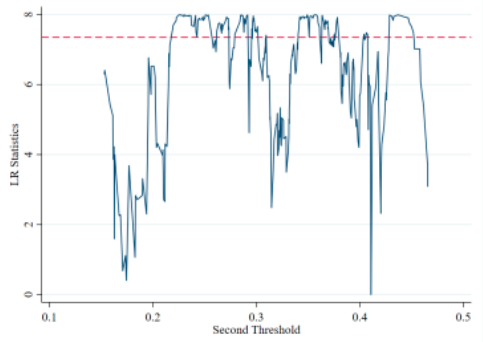

(b) Second threshold

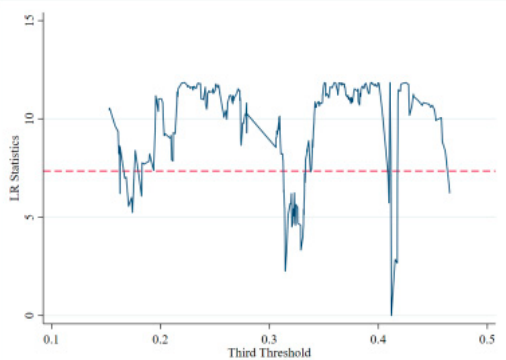

(c) Third threshold

Figure 4. Threshold estimation and confidence interval. (a) First threshold. (b) Second threshold. (c) Third threshold.

After estimating the threshold, we conduct threshold regression. As shown in Table 6, the coefficient of the threshold variable decreased from 0.6641 to 0.5281 , which indicates innovation presents a significant threshold effect on green growth: the role of innovation in driving green growth may be weakened in the long run but not in the short run. It may result from the fact that environmental costs increase with the development of the economy, so it offset the positive impact of innovation on economic growth. Accordingly, the role of innovation in promoting green growth may be weakened.

Table 6. Threshold regression results of the entire industry.

\begin{tabular}{|c|c|c|c|c|c|}
\hline \multicolumn{2}{|c|}{ Explanatory Variable } & \multirow{2}{*}{$\frac{\text { Coefficient }}{0.6641^{* * *}}$} & \multirow{2}{*}{$\begin{array}{c}\begin{array}{c}\text { Standard } \\
\text { Deviation }\end{array} \\
0.1169\end{array}$} & \multirow{2}{*}{$\frac{\text { t-Statistic }}{5.68}$} & \multirow{2}{*}{$\frac{p \text {-Value }}{0.000}$} \\
\hline & $\gamma_{1} \leq 0.2915$ & & & & \\
\hline $\mathrm{IE}$ & $\gamma_{1}>0.2915$ & $0.5281^{* * *}$ & 0.1300 & 4.06 & 0.000 \\
\hline Cap & & $0.2701^{* * *}$ & 0.0545 & 4.96 & 0.000 \\
\hline $\mathrm{Lab}$ & & $0.6687^{* * *}$ & 0.0802 & 8.34 & 0.000 \\
\hline Energy & & $-7.4542^{* * *}$ & 0.6863 & -10.86 & 0.000 \\
\hline Environment & & $6.2823 * * *$ & 1.7544 & 3.58 & 0.000 \\
\hline Market & & $1.9311^{* * *}$ & 0.2588 & 7.46 & 0.000 \\
\hline
\end{tabular}

*** indicate significant at $1 \%$ statistical levels. 
The regression results above prove that innovation could promote green growth significantly. In what follows, we analyzed the path of innovation promoting green growth from the theoretical and practical levels.

First of all, it is stated explicitly that according to OECD [22], green growth is a growth mode that ensures the continuous supply of resources and environmental services at the same time of economic development. Therefore, green growth contains double connotations: economic growth and environmental pollution. Both developing economy and reducing environmental pollution will promote green growth.

In the previous analysis, we proposed that the driving effect of innovation on green growth was weakened because the positive impact of innovation on economic growth was offset by the increasing environmental costs, which may not be rigorous. Because according to the Environmental Kuznets Curve (EKC), the relationship between economic growth and environmental pollution will vary as the economy develops: environmental pollution will become increasingly severe until the economic growth reaches a specific level. After that, as the economy grows, the environmental pressure will be alleviated. From the EKC, it can be seen that green growth is a two-stage growth: in the first stage, environmental pollution will be increasingly serious, so the green growth at this time is driven by economic development. In the second stage, environmental pollution will decrease gradually, so the green growth at this time is driven by the declining environmental costs. This indicates that if the economy lies in the second stage of the EKC, there may be a second explanation of our regression results: at this moment, the environmental cost will decrease as the economy grows. However, because the current level of economic development is higher than that in the first stage, the growth rate declines, which will restrict the promotion effect of innovation on economic growth and thereby weaken the driving effect of innovation on green growth. Therefore, if we want to clarify what causes the regression results in Table 6, we necessitate combining the EKC to judge the dynamic variation between economic growth and environmental pollution.

Before analysis, it should be noted that the EKC is the connection between all factors and the gross domestic product (GDP), while our dependent variable is green value-added. The connotation of GDP and green value-added is different: a country's GDP is the total value of goods and services produced within a country in a year, while green GDP is the total amount of real national wealth that is determined by deducting the cost of economic loss caused by environmental pollution, degradation of natural resources, low education, out of control of the population and poor management from the traditional GDP [53]. The reason why we mention the EKC here is that we hope to grasp the dynamic variation of economic growth and environmental pollution rather than use this curve to represent the path of driving green growth by innovation.

Based on the econometric equation, Lin and Jiang [54] predicted the theoretical inflection point of China's $\mathrm{CO}_{2}$ Kuznets Curve and found China's $\mathrm{CO}_{2}$ emissions would appear around 2020. Then, to predict the actual inflection point, first, they estimated the long-term equilibrium relationship of China's primary energy demand through the co-integration method and then predicted the dynamic change of China's primary energy consumption structure by the Markov probability analysis method. Based on the above prediction, they predicted China's $\mathrm{CO}_{2}$ emissions and $\mathrm{CO}_{2}$ Kuznets curve and found in their forecast interval of 2008-2040, per capita $\mathrm{CO}_{2}$ emissions increased as per capita income increases, so they presented that the actual inflection point of the $\mathrm{CO}_{2}$ Kuznets curve may exceed 2040.

However, Lin and Jiang's work [54] was published in 2009, so restricted by methodology, their prediction may not be accurate; that is, the actual inflection point of the $\mathrm{CO}_{2}$ Kuznets curve may not exceed 2040. This is because, to control carbon emissions, in 2015, China had proposed the carbon peak target. According to this target, $\mathrm{CO}_{2}$ emissions in China will no longer increase after 2030. Meanwhile, the population remains increasing as the economy grows, which means the per capita $\mathrm{CO}_{2}$ emissions will decline gradually after 2030. Therefore, the inflection point of the $\mathrm{CO}_{2}$ Kuznets curve should be earlier than 
2040 but later than 2030. It can be seen that no matter according to the research of Lin and Jiang [54], or according to the target of carbon peak, China's $\mathrm{CO}_{2}$ emissions are expected to decline after 2030, which proved that China had not crossed the inflection point of the $\mathrm{CO}_{2}$ Kuznets Curve during 2005-2016, so the environmental costs in China would become increasingly severe in this period. The above analysis confirms our original conjecture.

Through the above empirical analysis, we have proved the theoretical path of innovation to promote green growth. So, in the actual economic activities, what paths will innovation drive green growth? Referring to the existing studies, we indicate that innovation can promote green growth through the following two paths.

First, innovation may reduce the environmental impact by affecting the use of natural resources in industrial activities, thus directly promoting green growth. For the whole industry, for one thing, innovation can optimize the industrial structure by investing R\&D funds and R\&D personnel, improve the resource allocation efficiency and energy efficiency of the industry and ultimately reduce energy waste [55]. For another, innovation can gradually reduce the proportion of fossil energy in the energy consumption structure by promoting renewable energy $R \& D$, which will reduce carbon emissions and promote green growth. The path of innovation driving green growth also varies from industrial types. For traditional industries, innovation can update their production equipment and eliminate backward production capacity, thus improving resource allocation efficiency and energy utilization. For high-tech industries, considering that most of these industries are environment-friendly, innovation can promote green growth by promoting the development of these industries.

Second, at the social level, innovation indirectly promotes green growth by influencing residents' consumption habits and entrepreneurship. On the one hand, innovation will affect the consumption concept and then guide consumers to green consumption. Lao [56] proved that consumer innovation could affect consumers' green-consumption intention and behavior through influencing their attitude, subjective norms, and perceptual control of green consumption. On the other hand, the nature of an innovative economy is to stimulate the entrepreneurship of all members of the economy [57], and entrepreneurship will motivate enterprises to pursue green innovation and thereby promote green growth. Zhao et al. [58] took Chinese cities as the research object and discussed the relationship of the business environment, entrepreneurship, and green growth. It turned out that by cultivating entrepreneurship, the business environment positively affected green growth In short, besides the environment, innovation will also promote green growth at the social level.

The literature taking other countries as research objects also proves our results. Taking Turkey as the research object, Sohag et al. [59] examined the role of cleaner energy, technological innovation, and militarization on green economic growth and found that technological innovation would drive green economic growth in the long term. Ahmad et al. [60] also proved that ecological innovation will reduce the ecological footprint and promote the sustainable development of cities. Besides, some studies note that the impact of innovation on green growth may vary with regions. Mensah et al. [9] found that for the Oceanian subregion, transportation-related technologies would promote green growth, while for the Asian region, commodity production and processing technologies are more conducive to green growth. On the one hand, this result proves the positive impact of innovation on green growth; on the other hand, this result presents that different regions have different technologies suited to local conditions, which means promoting inappropriate technology may hinder green growth and weaken the role of innovation in green growth.

Stated in terms of control variables, the physical capital input, labor input, energy intensity, environmental regulation, and marketization all passed statistical tests at the $1 \%$ level. These results demonstrate that increasing physical capital input and labor input, decreasing energy intensity, strengthening environmental regulation, and marketizing contribute to green growth. There are some possible explanations for these results. As noted 
above, green growth has double connotations, including developing the economy and decreasing environmental pollution, so any measures to promote economic growth or reduce environmental pollution will promote green growth. Capital and labor are the basic factors of economic growth. Therefore, increasing capital and labor input will promote economic development and then promote green growth. Additionally, reducing energy intensity will directly reduce carbon emissions, thus reducing environmental costs and promoting green growth. The impact of marketization on green growth has also been proved by literature. Xie et al. [61] indicated that marketization promoted green growth by improving the distortion of labor market factors and capital market factors.

The relationship between environmental regulation and green growth is more complex. There are two hypotheses to elaborate on this relationship. One of them is the Porter Hypothesis [62], which indicates that environmental regulation induces firm innovation to reduce its compliance cost, so implementing environmental regulation can improve a firm's competitiveness and environmental quality. The other hypothesis is Pollution Refuge Hypothesis [63]. This Hypothesis presents that there are regional differences in environmental regulation, and these differences provide a refuge space for polluting enterprises, so environmental regulation will inhibit green growth. Yuan and Xiang [64] examined the Porter hypothesis of China's manufacturing industry and noted that environmental regulation improved the energy efficiency and environmental efficiency of the manufacturing industry. This research proves that if taking the industry as the research object, environmental regulation will improve environmental quality and thereby promote green growth, which proves our results.

\subsubsection{Regression Results by Industry Type}

As illustrated in Table 7, for the industries with higher green growth levels, the single threshold effect of innovation is significant but not for the industries with lower green growth levels. The threshold value of the industries with the higher green growth levels was 0.2792 , and the corresponding $95 \%$ confidence interval was $0.2782-0.2795$.

Table 7. Threshold effect test results by industry types.

\begin{tabular}{cccccccc}
\hline Industry Type & Test Type & $\begin{array}{c}\text { Threshold } \\
\text { Parameter }\end{array}$ & $\begin{array}{c}\text { Confidence } \\
\text { Interval }\end{array}$ & RSS & MSE & $\begin{array}{c}\text { F } \\
\text { Statistic }\end{array}$ & $p$-Value \\
\hline Industries with & Single threshold & 0.2915 & $0.2890-0.2922$ & 10.0554 & 0.0441 & 13.17 & 0.3860 \\
lower levels of & Double threshold & 0.4107 & $0.4101-0.4114$ & 9.5819 & 0.0420 & 11.27 & 0.4733 \\
green growth & Triple threshold & 0.4255 & $0.4202-0.4286$ & 9.2934 & 0.0408 & 7.08 & 0.7833 \\
\hline Industries with & Single threshold & 0.2792 & $0.2782-0.2795$ & 3.9856 & 0.0175 & 20.02 & 0.0440 \\
higher levels of & Double threshold & 0.3053 & $0.2534-0.3067$ & 4.0814 & 0.0179 & -5.35 & 1.0000 \\
green growth & Triple threshold & 0.3517 & $0.3516-0.3528$ & 4.0617 & 0.0178 & 1.11 & 0.8480 \\
\hline
\end{tabular}

In comparison, industries with lower green growth levels are confronted with higher abatement pressure. To reduce pollution, the government will regulate the production of enterprises by levying environmental taxes, which increases the production costs of these enterprises. To control the production cost, enterprises will reduce energy consumption and pollution emissions. Therefore, although these industries are confronted with higher abatement pressure under environmental regulation, their environmental costs will not significantly increase. For industries with higher green growth levels, their production will not be significantly influenced by environmental regulation, so the environmental cost for these industries will continue to increase and offset the positive impact of innovation on economic growth.

As presented in Table 8, identical to the regression results of the entire industry, after the threshold variable crosses the threshold, the coefficient of innovation-driven effect decreased. Moreover, except for environmental regulation variables, the coefficients and significance of most control variables were consistent with the earlier results, which proves the robustness of the results in this part. The reason for the negative coefficient of environ- 
mental regulation variable might be that for the industries with higher green growth levels, their environmental problems are relatively light, so excessive pollution treatment costs will lead to the waste of funds, and thus hamper green growth for these industries.

Table 8. Threshold regression results of industries with higher green growth levels.

\begin{tabular}{|c|c|c|c|c|c|}
\hline Explanato & Variable & Coefficient & $\begin{array}{l}\text { Standard } \\
\text { Deviation }\end{array}$ & t-Statistic & $p$-Value \\
\hline \multirow{2}{*}{ IE } & $\gamma_{1} \leq 0.2792$ & $0.9117^{* * *}$ & 0.1388 & 6.57 & 0.000 \\
\hline & $\gamma_{1}>0.2792$ & $0.8101^{* * *}$ & 0.1518 & 5.34 & 0.000 \\
\hline Cap & & $0.1992^{* * *}$ & 0.0490 & 4.06 & 0.000 \\
\hline $\mathrm{Lab}$ & & $0.7219^{* * *}$ & 0.0764 & 9.45 & 0.000 \\
\hline Energy & & $-5.4845^{* * *}$ & 1.5605 & -3.51 & 0.001 \\
\hline Environment & & $-15.0486^{* * *}$ & 4.5554 & -3.30 & 0.001 \\
\hline Market & & $1.5686^{* * *}$ & 0.2692 & 5.83 & 0.000 \\
\hline
\end{tabular}

\subsection{The Mechanism of Decreasing Energy Security Risks by Innovation}

\subsubsection{Model}

The threshold regression model is constructed as follows:

$$
\ln (E S R)=\beta_{1} \ln \left(I E_{i t}\right) I\left(I E_{i t} \leq \gamma_{2}\right)+\beta_{2} \ln \left(I E_{i t}\right) I\left(I E_{i t}>\gamma_{2}\right)+\beta_{3} X_{i t}+\mu_{i}+\varepsilon_{i t}
$$

In Equation (23), ESR is the energy security risk index, and $\gamma_{2}$ is the threshold parameter. Other variables are set the same as those in Equation (22).

\subsubsection{Variable Selection and Data Sources}

The Global Energy Institute selects 29 indicators from global fuels, fuel imports, energy expenditures, price and market volatility, energy use intensity, electric power sector, and transportation and constructs the International Index of Energy Security Risk to evaluate the vulnerability of 25 economies in the global energy market. It can be seen that in addition to China, this index also measures 24 other economies in the world energy market. Compared with the researches that only estimate the energy security level of China, this index can be used for international comparison, so this index is more objective and creditable. As a result, we selected China Index Scores from this Index to measure China's energy security risk.

As suggested by the literature review, energy supply security and environmental security are important components to energy security risk. The energy intensity (denoted as Energy) and carbon intensity (denoted as Carbon) reflect the energy consumption and abatement pressure of each industry, so the two indicators are inextricably linked with energy security risks. For one thing, energy intensity will increase as energy consumes, so the industries with higher energy intensity are generally confronted with higher energy security risks [15,65]. For another, higher carbon intensity induces greater abatement pressure and thus leads to a higher energy security risk. So carbon intensity also positively associates with the energy security risk.

Apart from energy intensity and carbon intensity, the industrial characteristics also affect energy security risk. First of all, factor intensity (denoted as Factor) is one of the critical factors that affect the energy security risk. Most capital-intensive industries are heavy manufacturing with large energy demand and high dependence on imported energy [66]. So these industries are generally confronted with higher energy security risks than laborintensive industries. We use per capita capital to represent factor intensity and assume that the per capita capital positively associates with the risk of energy security. The data of capital and labor comes from the third part. The openness degree (denoted as Open) also affects energy security risks, but its effect on energy security risks is more complicated. On the one hand, open improves energy efficiency and reduces pollution, thus decreasing the 
risk of energy security [67]. On the other hand, the higher the opening degree is, the closer the connection between the energy market in China and that in the international will be. The energy price changes from the international market will affect the stability of China's energy market and thus increase the energy security risk [68]. Other studies also pointed out that promoting the opening may stimulate energy consumption and increase external energy dependence [69]. In what follows, we will examine the effect of open on energy security risk through empirical research. The opening degree was measured by the ratio of import and export to added value, where the value-added data comes from the third part of this paper, and the import and export data of industries comes from the United Nations commodity trade statistics.

\subsubsection{Regression Results of the Entire Industry}

As demonstrated in Table 9, the results of the double threshold and triple threshold were not significant, while the result of the single threshold was significant at the $1 \%$ level. Thus we determined this model as a single threshold model, the threshold estimation was 0.2347 , and the corresponding $95 \%$ confidence interval was $0.2325-0.2351$.

Table 9. Thethreshold effect test results of the entire industry.

\begin{tabular}{ccccccc}
\hline Test Type & $\begin{array}{c}\text { Threshold } \\
\text { Parameter }\end{array}$ & $\begin{array}{c}\text { Confidence } \\
\text { Interval }\end{array}$ & RSS & MSE & F Statistic & $p$-Value \\
\hline Single threshold & 0.2347 & $0.2325-0.2351$ & 0.5263 & 0.0011 & 23.63 & 0.0480 \\
Double threshold & 0.3140 & $0.3116-0.3146$ & 0.5084 & 0.0011 & 16.54 & 0.3167 \\
Triple threshold & 0.1827 & $0.1785-0.1832$ & 0.4851 & 0.0010 & 22.49 & 0.8433 \\
\hline
\end{tabular}

As illustrated in Figure 5, the LR statistic corresponding to the first threshold was much less than the critical value of 7.35, while there are multiple thresholds for the second and third LR statistics. Combining the test results in Table 9, we could determine the model as a single threshold model.

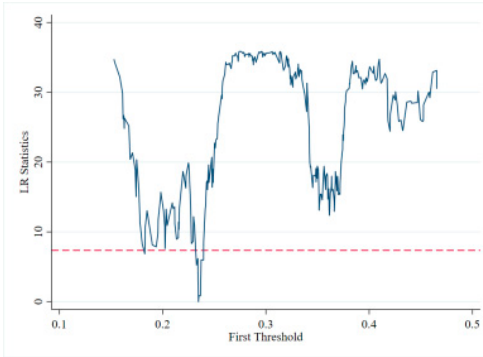

(a) First threshold

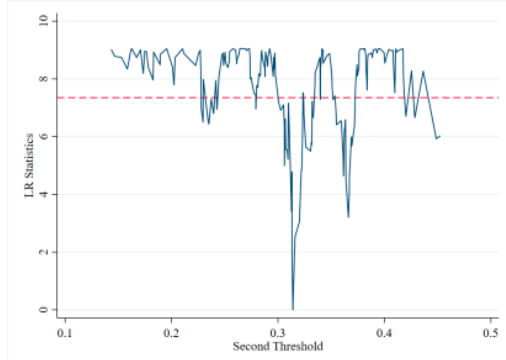

(b) Second threshold

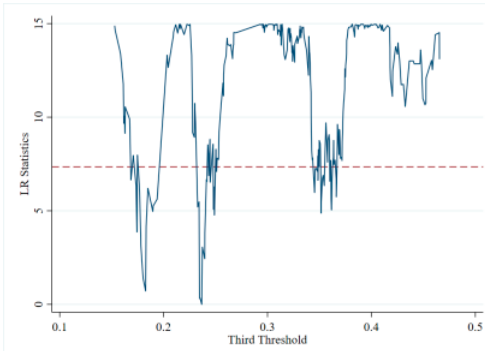

(c) Third threshold

Figure 5. Threshold estimation and confidence interval. (a) First threshold (b) Second threshold (c) Third threshold

Taking the innovation-driven effect of green growth as the threshold variable, we conduct threshold regression. The regression results are illustrated in Table 10. It can be seen that innovation had a significant threshold effect on energy security risk, and the coefficient of the threshold variable decreased from -0.1326 to -0.1553 . This result means that after the threshold crosses the threshold, innovation decreased energy security risks more significantly. The reason for this result may be that in the early stage, old equipment causes industries to face higher energy security risks. With the promotion of innovation, the equipment can be upgraded and improve energy efficiency. These improvements reduce the dependence of industrial production on imported energy and ultimately reduce the risk of energy security. 
Table 10. Threshold regression results of the entire industry.

\begin{tabular}{cccccc}
\hline Explanatory Variable & Coefficient & $\begin{array}{c}\text { Standard } \\
\text { Deviation }\end{array}$ & t-Statistic & $p$-Value \\
\hline \multirow{2}{*}{ IE } & $\gamma_{1} \leq 0.2347$ & $-0.1326^{* * *}$ & 0.0139 & -9.53 & 0.000 \\
& $\gamma_{1}>0.2347$ & $-0.1553^{* * *}$ & 0.0161 & -9.63 & 0.000 \\
\hline Energy & & $0.5930^{* * *}$ & 0.1320 & 4.49 & 0.000 \\
Carbon & $0.0020^{* * *}$ & 0.0006 & 3.37 & 0.001 \\
Factor & $0.0228^{* * *}$ & 0.0060 & 3.82 & 0.000 \\
Open & $0.0178^{* * *}$ & 0.0047 & 3.82 & 0.000 \\
\hline
\end{tabular}

*** indicate significant at $1 \%$ statistical levels.

Although the existing studies pay less attention to the relationship between innovation and energy security, there is a consensus that developing renewable energy through technological progress can improve energy security. Karatayev and Hall [70] compared the energy security performance of six Caspian countries and found limited by the high cost of renewable energy, Azerbaijan and Russia failed to achieve their 2020 renewable energy targets. Therefore, the government needs to promote technological progress to create conditions for the formation of a barrier-free renewable energy market, and thereby develop renewable energy, ensure energy security. The above research proves that technological progress can largely alleviate the pressure of energy shortage, which indirectly proves our results.

In terms of control variables, energy intensity, carbon intensity, factor intensity, and opening degree all passed the $1 \%$ significance level test. This result indicates that rising energy intensity, carbon intensity, capital input, and opening degree will increase energy security risk. This conclusion proves our original conjecture. First, industries with higher energy intensity consume more energy, so these industries are confronted with greater energy security risks. Similarly, industries with high energy intensity will have higher carbon emissions, which leads to greater environmental security risks for these industries. Furthermore, because most of the capital-intensive industries are manufacturing industries with high investment, high pollution, and high emissions, so these industries are confronted with greater energy security risks than labor-intensive industries. It is important to note that, according to our regression results, improving the opening degree will increase the risk of energy security. This may be because, although opening may improve energy efficiency and reduce environmental pollution, considering the decrease in pulling effect of China's exports on the economy [71], the stimulation of opening to improve energy efficiency and reduce pollution is also limited. As a result, improving the opening degree will increase the energy security risk.

\subsubsection{Regression Results by Industry Type}

To explore the industrial disparities of the impact of innovation on energy security risk, we test the threshold effect by industry type. As demonstrated in Table 11, the threshold variable in both industry types significantly expressed a single threshold effect. The threshold of industries with lower green growth levels was 0.2152 , and the corresponding $95 \%$ confidence interval was $0.2045-0.2154$. The threshold of industries with higher green growth levels was 0.1802 , and the corresponding $95 \%$ confidence interval was $0.1756-0.1849$. The results also present that industries with higher green growth levels had a lower threshold value, indicating that these industries can cross the threshold earlier. 
Table 11. Threshold effect test results by industry type.

\begin{tabular}{cccccccc}
\hline Industry Type & Test Type & $\begin{array}{c}\text { Threshold } \\
\text { Parameter }\end{array}$ & $\begin{array}{c}\text { Confidence } \\
\text { Interval }\end{array}$ & RSS & MSE & F Statistic & $\boldsymbol{p}$-Value \\
\hline Industries with & Single threshold & 0.2152 & $0.2045-0.2154$ & 0.2369 & 0.0010 & 17.12 & 0.0220 \\
lower levels of & Double threshold & 0.3140 & $0.3065-0.3160$ & 0.2276 & 0.0010 & 9.34 & 0.6267 \\
green growth & Triple threshold & 0.2351 & $0.2343-0.2373$ & 0.2207 & 0.0010 & 7.12 & 0.9767 \\
\hline Industries with & Single threshold & 0.1802 & $0.1756-0.1849$ & 0.2609 & 0.0011 & 27.64 & 0.0000 \\
higher levels of & Double threshold & 0.3121 & $0.3001-0.3123$ & 0.2475 & 0.0011 & 12.31 \\
green growth & Triple threshold & 0.2367 & $0.2300-0.2369$ & 0.2382 & 0.0010 & 8.90 & 0.1000 \\
\hline
\end{tabular}

We conducted threshold regression for the two industry types, and the results are demonstrated in Table 12. Comparing the results in Table 12 with those in Table 10, we found that the results of industries with lower green growth levels were closer to those of the entire industry. Moreover, due to the low energy security risks faced by the industries with higher green growth levels, their coefficient falls by more than those in other industries. This result indicated that we should focus more on the energy security of the industries with lower green growth levels and reduce their dependence on imported energy.

Table 12. Threshold regression results by industry types.

\begin{tabular}{|c|c|c|c|c|c|c|c|}
\hline \multicolumn{4}{|c|}{ Industries with Lower Green Growth Levels } & \multicolumn{4}{|c|}{ Industries with Higher Green Growth Levels. } \\
\hline \multicolumn{2}{|c|}{ Explanatory Variable } & \multirow{3}{*}{$\begin{array}{l}\text { Coefficient } \\
-0.1326^{* * *} \\
-0.1553^{* * *}\end{array}$} & \multirow{3}{*}{$\begin{array}{c}\begin{array}{c}\text { Standard } \\
\text { Deviation }\end{array} \\
0.0139 \\
0.0161 \\
\end{array}$} & \multicolumn{2}{|c|}{ Explanatory Variable } & \multirow{3}{*}{$\begin{array}{c}\text { Coefficient } \\
-0.0794^{* *} \\
-0.1292^{* * *}\end{array}$} & \multirow{3}{*}{$\begin{array}{c}\begin{array}{c}\text { Standard } \\
\text { Deviation }\end{array} \\
0.0241 \\
0.0228 \\
\end{array}$} \\
\hline & $\gamma_{2} \leq 0.2347$ & & & \multirow{2}{*}{ IE } & $\gamma_{2} \leq 0.2347$ & & \\
\hline $\mathrm{IE}$ & $\gamma_{2}>0.2347$ & & & & $\gamma_{2}>0.2347$ & & \\
\hline Energy & & $0.5930 * * *$ & 0.1320 & Energy & & 0.0818 & 0.4889 \\
\hline Carbon & & $0.0020^{* * *}$ & 0.0006 & Carbon & & $0.0051 *$ & 0.0029 \\
\hline Factor & & $0.0228^{* * *}$ & 0.0060 & Factor & & $0.0150^{* *}$ & 0.0063 \\
\hline Open & & $0.0178^{* * *}$ & 0.0047 & Open & & $0.0336^{* * *}$ & 0.0067 \\
\hline
\end{tabular}

$* * * * *, *$ indicate significant at $1 \%, 5 \%$, and $10 \%$ statistical levels respectively.

Expect for the energy intensity, the coefficients, and significance of other control variables were consistent with the results of the entire industry. Insignificant results of energy intensity were because industries with higher green growth levels had low energy consumption, so energy intensity had no significant effect on the energy security risk of these industries.

\section{Conclusions}

Examining the mechanism of driving green growth and decreasing energy security risks by innovation has important theoretical value and practical significance in constructing ecological civilization and ensuring energy security. Firstly, to analyze the theoretical mechanism of driving green growth by innovation and explore the role of innovation on green growth, we constructed a four-sector endogenous growth model including the final-goods sector, the intermediate-goods sector, the R\&D sector, and the energy sector. Secondly, to measure the driven effect of innovation on green growth, we derived the expression of innovation-driven effect and measured this effect of green growth in 40 industries from 2005 to 2016. Thirdly, to measure green industrial growth, we calculated the green added value of industries based on the SEEA. Fourthly, we used the threshold regression model to explore the mechanism of driving green growth and decreasing energy security risks by innovation, and referring to the existing literature, we determined the variables which may affect this mechanism. Finally, we put forward the corresponding policy recommendations.

The conclusions are as follows. 
(1) By deriving the endogenous growth model, we demonstrated that innovation promotes green growth by increasing intermediate-goods types, improving the intermediategoods quality, influencing the interest rate, promoting renewable energy research and development, and improving environmental quality. In addition, according to our calculation, the innovation-driven effect of green growth is the result of multiple factors in an economy. This effect is related to the human capital allocation proportion, the output elasticity of human capital, the output elasticity of intermediate-goods, the proportion of fossil-energy and clean-energy production in primary energy production, the growth rate of clean energy production, the discount rate, the environmental self-purification rate, the growth rate of fossil-energy recoverable reserves, the impact of technological progress on environmental quality, and the impact of technology on interest rates.

(2) The innovation-driven effect increased from 0.2729 in 2005 to 0.3446 in 2016, increasing by $26.3 \%$ in 12 years with an average growth rate of $2.2 \%$. Industries with higher innovation-driven effects are generally distributed in capital-intensive industries, while industries with lower innovation-driven effects are distributed in labor-intensive industries. Additionally, the average growth rate of industries with higher innovation-driven effects was lower than that of industries with lower innovation-driven effects. The above conclusions indicate that to promote green growth with innovation, China should implement differentiated policies based on industrial characteristics.

(3) The proportion of the green added value in the traditionally added value increased from $79.54 \%$ in 2005 to $92.25 \%$ in 2016, which indicates that the negative impact of China's economic development on resources and the environment is gradually weakening. The calculated result also suggests that the growth rate of the green added value of industries with lower green growth levels was higher than that of industries with higher green growth levels.

(4) Innovation had a significant threshold effect on green growth: the role of innovation in driving green growth may weaken in the long run but not in the short run. The regression results by industry type indicate that the single threshold effect of innovation on the industries with higher green growth levels is significant but not on the industries with lower green growth levels. This is because although industries with lower green growth levels are confronted with higher abatement pressure, under environmental regulation, their environmental costs will not significantly increase. So for these industries, the role of innovation on green growth will not be weakened as the economy develops.

Referring to the related literature on green growth, we select physical capital input, labor input, energy intensity, environmental regulation, and marketization as the control variables. The regression results indicate that the physical capital input, labor input, energy intensity, environmental regulation, and marketization all passed statistical tests at the $1 \%$ level, which demonstrates that increasing physical capital input and labor input, decreasing energy intensity, strengthening environmental regulation, and marketizing contribute to green growth.

(5) Innovation also has significant threshold characteristics on energy security risk: after the innovation-driven effect crosses the threshold, innovation decreases energy security risk more significantly. The regression results by industry type present that the innovation has a significant single threshold effect in the two industry types. However, industries with higher green growth levels can cross the threshold earlier, and their coefficient falls by more than other industries.

Referring to the related literature on green growth, we select energy intensity, factor intensity, carbon intensity, and openness degree as the control variables. The regression results indicated that energy intensity, carbon intensity, factor intensity, and opening degree all passed the $1 \%$ significance level test, which means that rising energy intensity, carbon intensity, capital input, and opening degree will increase energy security risk.

According to the above results, we propose the following three policy suggestions:

(1) Government should not use a "one size fits all" approach but formulate green development suited to industrial characteristics. On the one hand, the government should 
focus on the green growth of key industries and promote the green transformation of these industries; on the other hand, the government should coordinate the development among industries: while promoting the development of high-tech industries, the government should recognize the importance of the technological upgrading of labor-intensive industries.

(2) Given that innovation can decrease energy security risk, the government should increase R\&D investment through multiple channels to encourage energy innovation and develop renewable energy, and gradually increase the proportion of clean energy consumption in total energy consumption.

(3) By contrast, industries with lower green growth levels are facing higher energy security risks. Therefore, the government should improve the energy efficiency of these industries and reduce their external energy dependence. Moreover, according to our results, under the environmental regulation, the environmental costs in the industries with higher green growth levels will increase but not in the industries with lower green growth levels. This indicates that government should not only regulate the production of high pollution industries but also encourage industries with higher green growth levels to participate in energy conservation and emission reduction.

This research had the following limitations:

Firstly, the model could be further improved. On the one hand, in the theoretical model, we only considered the impact of innovation on renewable energy. In fact, in addition to promoting renewable energy $R \& D$, energy security could also be ensured by strengthening multilateral cooperation with other countries or maintaining the stability of the energy market. Therefore, in the follow-up analysis, we will consider more factors that affect energy security in the theoretical model. On the other hand, our research only studied the impact of innovation on green growth and energy security in China, so in a follow-up study, we will extend our research objects to other countries, revise our model based on the literature from other countries, and compare the results of this paper with that of the next paper.

Secondly, with the improvement of relevant data, our research can be further promoted in measurement. For one thing, the accounting scope of green added value can be further expanded. When calculating environmental cost, we only consider the cost of $\mathrm{CO}_{2}$ emission, $\mathrm{SO}_{2}$ emission, wastewater emission, and fossil energy consumption. In addition to the above four costs, the solid waste emission cost, the water resources consumption cost, and the land consumption cost can also be included in the accounting of environmental cost. In our follow-up study, we will expand the accounting scope of green added value. Second, due to data limitations, we only took energy intensity, carbon intensity, factor intensity, and the opening degree as control variables into the regression model of energy security risk. With the improvement of industry data, we will include more variables into the regression model and consider accounting for the energy security risk index of industries.

Author Contributions: Conceptualization, F.W.; methodology, R.W.; data curation, R.W.; investigation, R.W.; formal analysis, R.W.; writing-original draft preparation, R.W.; writing-review and editing, R.W.; supervision, F.W.; project administration, F.W.; Funding acquisition, F.W. Both authors have read and agreed to the published version of the manuscript.

Funding: This research was funded by the National Natural Science Foundation of China, grant number 71673217.

Institutional Review Board Statement: Not applicable.

Informed Consent Statement: Not applicable.

Data Availability Statement: The data are not publicly available due to the continuation of research and other manuscripts that are in process.

Conflicts of Interest: The authors declare no conflict of interest. 


\section{Appendix A}

The derivation of Equations (16)-(19) is given below.

First, we needed to deduce the expression of the monopoly price $\bar{P}$.

According to Dixit and Stiglitz [72], in symmetric equilibrium, the input price and scale of intermediate products are equal, so $P(i)=P$ and $x(i)=x$. By substituting the expression of $\mathrm{G}$ into Equation (1), we can get the following results:

$$
Y=\left(K_{Y}^{\alpha} L_{Y}^{\beta} R^{\gamma} E^{\theta}\right)^{1-v}\left(A^{\frac{\eta+1}{\sigma}} x\right)^{v}=\left(K_{Y}^{\alpha} L_{Y}^{\beta} R^{\gamma} E^{\theta}\right)^{1-v} A^{\frac{(\eta+1) v}{\sigma}} x^{v}
$$

By substituting Equation (A1) into Equation (2), the profit function of the final-goods sector can be expressed as:

$$
\pi_{1}=\left(K_{Y}^{\alpha} L_{Y}^{\beta} R^{\gamma} E^{\theta}\right)^{1-v} A^{\frac{(\eta+1) v}{\sigma}} x^{v}-w L_{Y}-r K_{Y}-P A^{\eta+1} x-P_{R} R-P_{E} E
$$

Based on the profit maximization condition, we obtain partial derivatives of $K_{Y}, L_{Y}$, and $x$ in Equation (A2), respectively. The results are presented as follows:

$$
\begin{gathered}
r=\alpha(1-v) \frac{Y}{K_{Y}} \\
w=\beta(1-v) \frac{Y}{L_{Y}} \\
P=v\left(K_{Y}^{\alpha} L_{Y}^{\beta} R^{\gamma} E^{\theta}\right)^{1-v} A^{(\eta+1) \frac{v-\sigma}{\sigma}} \mathrm{x}^{v-1}
\end{gathered}
$$

By solving the inverse demand function of Equation (A5), we can get Equation (A6):

$$
x=\left[\frac{v}{P}\right]^{\frac{1}{1-\nu}} A^{\frac{v-\sigma}{\sigma(1-v)}(\eta+1)} K_{Y}^{\alpha} L_{Y}^{\beta} R^{\gamma} E^{\theta}
$$

According to $P(i)=P$ and $x(i)=x$, and substituting the inverse demand function into Equation (3), we can get the profit function $\pi_{2}(i)$ as follows:

$$
\pi_{2}(i)=\pi_{2}=v\left(K_{Y}^{\alpha} L_{Y}^{\beta} R^{\gamma} E^{\theta}\right)^{1-v} A^{(\eta+1) \frac{v-\sigma}{\sigma}} A^{\eta} x^{v}-c A^{\eta} x
$$

By finding the partial derivative of $x$ in equation (A7), we can obtain the monopoly price of the intermediate-goods sector as follows.

$$
\bar{P}=\frac{c}{v}
$$

Second, based on the above results, we continue to derive Equations (16) and (17).

By substituting Equation (A6) and Equation (A8) into Equation (A1), the production function can be expressed as:

$$
Y=K_{Y}^{\alpha} L_{Y}^{\beta} R^{\gamma} E^{\theta}\left(\frac{v^{2}}{c}\right)^{\frac{v}{1-v}} A^{\frac{v(1-\sigma)(\eta+1)}{\sigma(1-v)}}
$$

Thus, Equation (A3) and Equation (A4) can be re-written as follows:

$$
\begin{aligned}
& r=\alpha(1-v) \frac{K_{Y}^{\alpha} L_{Y}^{\beta} R^{\gamma} E^{\theta}\left(\frac{v^{2}}{c}\right)^{\frac{v}{1-v}} A^{\frac{v(1-\sigma)(\eta+1)}{\sigma(1-v)}}}{K_{Y}} \\
& w=\beta(1-v) \frac{K_{Y}^{\alpha} L_{Y}^{\beta} R^{\gamma} E^{\theta}\left(\frac{v^{2}}{c}\right)^{\frac{v}{1-v}} A^{\frac{v(1-\sigma)(\eta+1)}{\sigma(1-v)}}}{L_{Y}}
\end{aligned}
$$


Then we derive the expressions of innovation research department $w$ and $r$. According to the profit maximization conditions, we set the R\&D sector's profit function as follows:

$$
\pi_{3}=P_{A} \times \dot{A}-w L_{A}-r K_{A}=P_{A} \times \delta L_{A} A-w L_{A}-r K_{A}
$$

For the partial derivatives of $K_{A}$ and $L_{A}$ in the above equation, we can obtain the expressions of $r$ and $w$ as follows:

$$
\begin{gathered}
r=P_{A} \times \delta L_{A} A \\
w=P_{A} \times \delta K_{A} A
\end{gathered}
$$

In Equations (A12) and (A13), $P_{A}$ and $\delta A$ are unknown variables, so we necessitate transforming these two variables.

First, the expression of $\delta A$ is deduced. According to the above assumption, under the equilibrium condition, the growth rate is g, so there is $\dot{A} / A=g$. Then according to Equation (4), we can get $\dot{A}=A g=\delta K_{A} L_{A} A$, so there is:

$$
\delta A=\frac{A g}{K_{A} L_{A}}
$$

Next, we derive the expression of $P_{A}$. According to Equation (5), $P_{A}$ can be expressed as:

$$
P_{A}=\int_{t}^{\infty} \pi_{2}(s) e^{-\bar{r}(s-t)} d s=\frac{1}{\bar{r}} \pi_{2}=\frac{1}{\xi A \mathrm{r}} \pi_{2}
$$

To simplify the model, we suppose that an intermediate-goods manufacturer can use 1 unit of capital to convert 1 unit of final good into 1 unit of intermediate-good; thus, we can get $Q(i)=Y$. According to $Q(i)=A^{\eta} x$, we substitute Equation (A8) and Equation (A9) into Equation (A7), and finally transform Equation (A7) into Equation (A16) as follows:

$$
\pi_{2}=c \frac{1-v}{v} K_{Y}^{\alpha} L_{Y}^{\beta} R^{\gamma} E^{\theta}\left(\frac{v^{2}}{c}\right)^{\frac{v}{1-v}} A^{\frac{v(1-\sigma)(\eta+1)}{\sigma(1-v)}}
$$

Substituting Equation (A16) into Equation (A15), we can re-write the $P_{A}$ expression as follows:

$$
P_{A}=\frac{1}{\xi A \mathrm{r}} \pi_{2}=\frac{c(1-v)}{\xi A \mathrm{r} v} K_{Y}^{\alpha} L_{Y}^{\beta} R^{\gamma} E^{\theta}\left(\frac{v^{2}}{c}\right)^{\frac{v}{1-v}} A^{\frac{v(1-\sigma)(\eta+1)}{\sigma(1-v)}}
$$

Substituting Equation (A14) and Equation (A17) into Equation (A12) and Equation (A13), the expressions of $r$ and $w$ in the R\&D sector can be obtained as:

$$
\begin{gathered}
r=\frac{(1-v) g}{\xi v K_{A}} K_{Y}^{\alpha} L_{Y}^{\beta} R^{\gamma} E^{\theta}\left(\frac{v^{2}}{c}\right)^{\frac{v}{1-v}} A^{\frac{v(1-\sigma)(\eta+1)}{\sigma(1-v)}} \\
w=\frac{(1-v) g}{\xi v L_{A}} K_{Y}^{\alpha} L_{Y}^{\beta} R^{\gamma} E^{\theta}\left(\frac{v^{2}}{c}\right)^{\frac{v}{1-v}} A^{\frac{v(1-\sigma)(\eta+1)}{\sigma(1-v)}}
\end{gathered}
$$

Under equilibrium conditions, the return rate on human capital and physical capital of the final-goods sector and the R\&D sector should be equal, so the Equation (A18) should be equal to Equation (A10) and Equation (A19) should be equal to Equation (A11). This relationship can be expressed by Equations (A20) and (A21)

$$
r=\alpha(1-v) \frac{K_{Y}^{\alpha} L_{Y}^{\beta} R^{\gamma} E^{\theta}\left(\frac{v^{2}}{c}\right)^{\frac{v}{1-v}} A^{\frac{v(1-\sigma)(\eta+1)}{\sigma(1-v)}}}{K_{Y}}=\frac{(1-v) g}{\xi \nu K_{A}} K_{Y}^{\alpha} L_{Y}^{\beta} R^{\gamma} E^{\theta}\left(\frac{v^{2}}{c}\right)^{\frac{v}{1-v}} A^{\frac{v(1-\sigma)(\eta+1)}{\sigma(1-v)}}
$$




$$
w=\beta(1-v) \frac{K_{Y}^{\alpha} L_{Y}^{\beta} R^{\gamma} E^{\theta}\left(\frac{v^{2}}{c}\right)^{\frac{v}{1-v}} A^{\frac{v(1-\sigma)(\eta+1)}{\sigma(1-v)}}}{L_{Y}}=\frac{(1-v) g}{\xi \nu L_{A}} K_{Y}^{\alpha} L_{Y}^{\beta} R^{\gamma} E^{\theta}\left(\frac{v^{2}}{c}\right)^{\frac{v}{1-v}} A^{\frac{v(1-\sigma)(\eta+1)}{\sigma(1-v)}}
$$

Reducing the Equation (A21), we can get Equation (A22):

$$
g L_{Y}=\beta \xi \nu L_{A}
$$

According to the optimality condition and Equation (12), Equation (13), and Equation (15), we can deduce Equation (A23).

$$
g=\frac{b-\mu \kappa+j \varphi}{\zeta}
$$

By substituting Equation (A23) into Equation (A22), Equation (A22) can be transformed into Equation (A24):

$$
L_{Y}(b-\mu \kappa+j \varphi)=\beta \xi \nu \zeta L_{A}
$$

According to $L=L_{Y}+L_{A}$ and Equation (A23), $L_{Y}$ and $L_{A}$ can be expressed as:

$$
\begin{aligned}
& L_{Y}=\frac{\beta \xi \nu \zeta}{\beta \xi \nu \zeta+b-\mu \kappa+j \varphi} L \\
& L_{A}=\frac{b-\mu \kappa+j \varphi}{\beta \xi \nu \zeta+b-\mu \kappa+j \varphi} L
\end{aligned}
$$

According to the optimality condition, which is Equation (14), we can obtain $r=\rho+g$. Referring to Tao and Peng [18], we assumed that under the general equilibrium condition, the interest cost per unit of the capital of the intermediate-goods sectors was equal to the unit cost of physical capital, that is, $c=r$, then we can get $c=\rho+g$. By substituting $c=\rho+g$ and Equation (A23) into Equation (A9), the production function of the final-goods sector can be transformed into:

$$
Y=K_{Y}^{\alpha} L_{Y}^{\beta} R^{\gamma} E^{\theta}\left(\frac{\zeta v^{2}}{\rho \zeta+b-\mu \kappa+j \varphi}\right)^{\frac{v}{1-v}} A^{\frac{v(1-\sigma)(\eta+1)}{\sigma(1-v)}}
$$

According to the Solow residual method, we can get the following equation:

$$
E_{A}=1-\alpha\left(\frac{\zeta v^{2}}{\rho \zeta+b-\mu \kappa+j \varphi}\right)^{\frac{\xi}{1-\tilde{\xi}}}-\beta\left(\frac{\zeta v^{2}}{\rho \zeta+b-\mu \kappa+j \varphi}\right)^{\frac{\xi}{1-\tilde{\xi}}}-\gamma\left(\frac{\zeta v^{2}}{\rho \zeta+b-\mu \kappa+j \varphi}\right)^{\frac{\xi}{1-\tilde{\xi}}}-\theta\left(\frac{\zeta v^{2}}{\rho \zeta+b-\mu \kappa+j \varphi}\right)^{\frac{\xi}{1-\tilde{\xi}}}
$$

According to $\alpha+\beta+\gamma+\theta=1$, we can convert the above equation into:

$$
E_{A}=1-\left(\frac{\zeta v^{2}}{\rho \zeta+b-\mu \kappa+j \varphi}\right)^{\frac{v}{1-v}}
$$

By substituting Equation (16) and Equation (17) into the above equation, we can obtain the expression of the innovation-driven effect of green growth as follows:

$$
E_{A}=1-\left(\frac{L_{Y}}{L_{A}} \times \frac{(b-\mu \kappa-j \varphi) v}{\left(\rho \zeta^{2}+b-\mu \kappa-j \varphi\right) \beta \xi}\right)^{\frac{v}{1-v}}
$$




\section{Appendix B}

\section{Appendix B.1. Estimation and Adjustment of Capital Investment}

The existing researches mostly adopt the perpetual inventory method (PIM) of Goldsmith [73] to estimate the physical capital stock. Therefore, we also choose this method to measure the physical capital stock:

$$
K_{\mathrm{t}}=K_{t-1}+I_{t}-\delta_{t} K_{t-1}
$$

Among them, $K_{t}$ is the capital stock of period $t, K_{t-1}$ is the capital stock of period $t-1$, $I_{t}$ is the total investment amount of comparable price of period $t$, and $\delta_{t}$ is the depreciation rate of physical capital of period $t$.

The estimation of the physical capital stock of industries by using the PIM involves the determination of three indicators (i.e., the initial capital stock $K$, the depreciation rate $\delta$ of industries, and the total investment $I$ of comparable prices of industries). The determination methods of these three indicators will be described in the following.

First, we need to determine the depreciation rate $\delta$ by industry. The existing literature often assumes that the depreciation rate is a constant and then estimates the capital stock by this rate. However, due to the differences in capital accumulation and structure among different industries, so we should estimate different depreciation rates for different industries. We can use the following equation to estimate depreciation rate by industry:

$$
\begin{gathered}
A D D_{\mathrm{t}}=F A_{t}-F_{t} \\
T D_{\mathrm{t}}=A D D_{t}-A D D_{t-1} \\
\delta_{t}=T D_{t} / F A_{t-1}
\end{gathered}
$$

where $A D D$ represents accumulated depreciation, $F A$ represents the original value of fixed assets, $F$ represents a net value of fixed assets, $T D$ represents a depreciation of this year, $\delta$ represents depreciation rate, and subscript $t$ and subscript $t-1$ represent current period and previous period, respectively. The data for the original value and accumulated depreciation of fixed assets were from the China Industrial statistical yearbook. The current year's depreciation of period $t$ is the accumulated depreciation of period $t$ minus the accumulated depreciation of period $t-1$, where the depreciation rate of the industry in the period $t$ is calculated by dividing the depreciation of the current year in the period $t$ by the original value of the fixed assets in the period $t-1$. It should be noted that the depreciation rate cannot be negative. If the industry depreciation rate in period $t$ is negative, the average value of depreciation rate in period $t-1$ and period $t+1$ will be used instead.

Secondly, we should determine the comparable price and the total amount of investment I. Specifically, we determine the total caliber investment amount of comparable price by determining the annual new investment amount and the price index for the adjustment of the new investment amount. The data for the original value of fixed assets came from the China Industrial Statistical Yearbook. The amount of new investment in the period $t$ can be calculated by subtracting the original value of fixed assets in the period $t-1$ from that in the period $t$. It should be noted that the negative calculation result means that there is no investment in the current year, so the new investment is recorded as 0 . The calculation equation of annual new investment in period $t$ is as follows:

$$
N I_{\mathrm{t}}=F A_{t}-F A_{t-1}
$$

where NI represents the new investment at the current price. Same as the equivalent value of gross industrial output value, new investment at the current price is also affected by price fluctuation. Therefore, to compare new investments in different years, a fixed base period should be selected to adjust the amount of new investment to the amount of comparable investment. To get the comparable investment in 1990 as the base period, we set the fixed 
assets investment price index $(1990=100)$ as $F P I_{t-1}$ and used this index to reduce the new investment in the current year:

$$
I_{\mathrm{t}}=N I_{t} \div F P I_{t-1}
$$

Finally, we determine the initial capital stock. According to the PIM, the earlier the year of the initial capital stock is selected, the smaller the impact of the estimation on the subsequent years and the more accurate the estimation will be. Considering the availability of other input data, we select 1980 as the year of initial capital stock.

\section{Appendix B.2. Estimation of Labor Input}

As far as the original data is concerned, the labor data from 2005 to 2011 came from the China Statistical Yearbook, while the 2012 to 2014 data came from the CSMAR database. In addition, the statistical caliber of labor data in the China Statistical Yearbook from 2015 to 2016 has changed, so we adjusted the labor data caliber from 2005 to 2016 based on the principle of labor data caliber adjustment by Chen [41].

After obtaining the labor data, referring to the method of Fan [40], we calculated the total human capital. Firstly, we divide the employees of industries into five groups according to their education level: illiterate (illiterate or illiterate), primary school, junior high school, senior high school, and university (including junior college and undergraduate). Secondly, according to the years of education of each group, we give weights of $0,6,9,12$, and 16, respectively. Then, by summing the number of employees of each group and their weights, we finally get the total human capital of industries.

\section{Appendix C}

Table A1. Estimation of human capital allocation proportion from 2005 to 2016.

\begin{tabular}{|c|c|c|c|c|c|c|c|c|c|c|c|c|}
\hline Industry Code & 2005 & 2006 & 2007 & 2008 & 2009 & 2010 & 2011 & 2012 & 2013 & 2014 & 2015 & 2016 \\
\hline I1 & 0.0948 & 0.0957 & 0.0969 & 0.1057 & 0.1101 & 0.1175 & 0.1232 & 0.1258 & 0.1321 & 0.1365 & 0.1304 & 0.1304 \\
\hline I2 & 0.2755 & 0.2919 & 0.2682 & 0.2349 & 0.4691 & 0.5578 & 0.6211 & 0.7651 & 0.7277 & 0.8109 & 0.9622 & 1.0144 \\
\hline $\mathrm{I} 3$ & 0.8920 & 0.9285 & 0.8685 & 0.7558 & 1.3152 & 1.5640 & 1.7412 & 2.1449 & 2.0403 & 2.2733 & 2.6976 & 2.8440 \\
\hline $\mathrm{I} 4$ & 0.2367 & 0.2505 & 0.2304 & 0.2017 & 0.4132 & 0.4913 & 0.5470 & 0.6738 & 0.6410 & 0.7142 & 0.8475 & 0.8935 \\
\hline I5 & 0.2667 & 0.2813 & 0.2596 & 0.2271 & 0.4689 & 0.5575 & 0.6207 & 0.7647 & 0.7273 & 0.8104 & 0.9617 & 1.0139 \\
\hline I6 & 0.1480 & 0.1569 & 0.1441 & 0.1262 & 0.2661 & 0.3164 & 0.3523 & 0.4340 & 0.4128 & 0.4600 & 0.5458 & 0.5754 \\
\hline I7 & 0.1929 & 0.2280 & 0.2136 & 0.2306 & 0.2706 & 0.3408 & 0.3889 & 0.4071 & 0.4507 & 0.4807 & 0.5070 & 0.4904 \\
\hline I8 & 0.2799 & 0.3298 & 0.3091 & 0.3333 & 0.3767 & 0.4745 & 0.5415 & 0.5669 & 0.6275 & 0.6693 & 0.7059 & 0.6827 \\
\hline I9 & 0.2983 & 0.3506 & 0.3287 & 0.3542 & 0.4004 & 0.5044 & 0.5756 & 0.6025 & 0.6670 & 0.7114 & 0.7503 & 0.7257 \\
\hline I10 & 0.6410 & 0.7522 & 0.7053 & 0.7598 & 0.7196 & 0.9065 & 1.0343 & 1.0828 & 1.1986 & 1.2784 & 1.3484 & 1.3041 \\
\hline I11 & 0.1274 & 0.1510 & 0.1414 & 0.1527 & 0.1842 & 0.2320 & 0.2648 & 0.2772 & 0.3068 & 0.3273 & 0.3452 & 0.3338 \\
\hline I12 & 0.1206 & 0.1434 & 0.1342 & 0.1451 & 0.1730 & 0.2179 & 0.2487 & 0.2603 & 0.2882 & 0.3074 & 0.3242 & 0.3135 \\
\hline I13 & 0.1153 & 0.1374 & 0.1286 & 0.1390 & 0.1651 & 0.2079 & 0.2372 & 0.2484 & 0.2749 & 0.2932 & 0.3093 & 0.2991 \\
\hline I14 & 0.1204 & 0.1430 & 0.1339 & 0.1447 & 0.1738 & 0.2189 & 0.2498 & 0.2615 & 0.2895 & 0.3088 & 0.3257 & 0.3150 \\
\hline I15 & 0.1577 & 0.1872 & 0.1753 & 0.1894 & 0.2224 & 0.2802 & 0.3197 & 0.3347 & 0.3705 & 0.3952 & 0.4168 & 0.4031 \\
\hline I16 & 0.1878 & 0.2219 & 0.2079 & 0.2244 & 0.2643 & 0.3330 & 0.3799 & 0.3977 & 0.4403 & 0.4696 & 0.4953 & 0.4790 \\
\hline I17 & 0.2521 & 0.2961 & 0.2776 & 0.2992 & 0.3483 & 0.4387 & 0.5006 & 0.5241 & 0.5802 & 0.6188 & 0.6526 & 0.6312 \\
\hline I18 & 0.1298 & 0.1544 & 0.1445 & 0.1562 & 0.1849 & 0.2330 & 0.2658 & 0.2783 & 0.3080 & 0.3286 & 0.3465 & 0.3352 \\
\hline I19 & 0.4926 & 0.5752 & 0.5397 & 0.5807 & 0.6055 & 0.7628 & 0.8704 & 0.9112 & 1.0086 & 1.0758 & 1.1346 & 1.0974 \\
\hline I 20 & 0.3469 & 0.4072 & 0.3818 & 0.4114 & 0.4545 & 0.5725 & 0.6532 & 0.6838 & 0.7570 & 0.8074 & 0.8516 & 0.8236 \\
\hline $\mathrm{I} 21$ & 0.6644 & 0.7730 & 0.7257 & 0.7800 & 0.7557 & 0.9519 & 1.0862 & 1.1371 & 1.2587 & 1.3425 & 1.4159 & 1.3695 \\
\hline I22 & 0.3338 & 0.3919 & 0.3675 & 0.3960 & 0.4404 & 0.5547 & 0.6329 & 0.6626 & 0.7335 & 0.7823 & 0.8251 & 0.7980 \\
\hline $\mathrm{I} 23$ & 0.1964 & 0.2321 & 0.2174 & 0.2346 & 0.2751 & 0.3466 & 0.3954 & 0.4140 & 0.4582 & 0.4888 & 0.5155 & 0.4986 \\
\hline I 24 & 0.1829 & 0.2163 & 0.2026 & 0.2187 & 0.2576 & 0.3245 & 0.3703 & 0.3877 & 0.4291 & 0.4577 & 0.4827 & 0.4669 \\
\hline I 25 & 0.1470 & 0.1744 & 0.1633 & 0.1764 & 0.2093 & 0.2636 & 0.3008 & 0.3149 & 0.3486 & 0.3718 & 0.3921 & 0.3793 \\
\hline I26 & 0.3257 & 0.3816 & 0.3579 & 0.3854 & 0.4348 & 0.5477 & 0.6250 & 0.6543 & 0.7242 & 0.7725 & 0.8147 & 0.7880 \\
\hline $\mathrm{I} 27$ & 0.3102 & 0.3649 & 0.3421 & 0.3687 & 0.4123 & 0.5193 & 0.5926 & 0.6203 & 0.6867 & 0.7324 & 0.7725 & 0.7471 \\
\hline $\mathrm{I} 28$ & 0.2185 & 0.2580 & 0.2418 & 0.2609 & 0.3024 & 0.3809 & 0.4346 & 0.4550 & 0.5036 & 0.5372 & 0.5665 & 0.5480 \\
\hline I29 & 0.2958 & 0.3479 & 0.3262 & 0.3516 & 0.3964 & 0.4994 & 0.5698 & 0.5965 & 0.6603 & 0.7043 & 0.7428 & 0.7184 \\
\hline
\end{tabular}


Table A1. Cont.

\begin{tabular}{ccccccccccccc}
\hline Industry Code & $\mathbf{2 0 0 5}$ & $\mathbf{2 0 0 6}$ & $\mathbf{2 0 0 7}$ & $\mathbf{2 0 0 8}$ & $\mathbf{2 0 0 9}$ & $\mathbf{2 0 1 0}$ & $\mathbf{2 0 1 1}$ & $\mathbf{2 0 1 2}$ & $\mathbf{2 0 1 3}$ & $\mathbf{2 0 1 4}$ & $\mathbf{2 0 1 5}$ & $\mathbf{2 0 1 6}$ \\
\hline I30 & 0.4151 & 0.4856 & 0.4555 & 0.4903 & 0.5292 & 0.6665 & 0.7606 & 0.7962 & 0.8814 & 0.9401 & 0.9915 & 0.9590 \\
I31 & 0.4031 & 0.4718 & 0.4426 & 0.4765 & 0.5165 & 0.6506 & 0.7424 & 0.7772 & 0.8603 & 0.9176 & 0.9678 & 0.9361 \\
I32 & 0.3240 & 0.3806 & 0.3569 & 0.3845 & 0.4291 & 0.5405 & 0.6167 & 0.6456 & 0.7147 & 0.7622 & 0.8039 & 0.7776 \\
I33 & 0.3904 & 0.4554 & 0.4274 & 0.4597 & 0.5097 & 0.6421 & 0.7327 & 0.7670 & 0.8490 & 0.9056 & 0.9551 & 0.9238 \\
I34 & 0.4493 & 0.5266 & 0.4938 & 0.5318 & 0.5588 & 0.7039 & 0.8032 & 0.8409 & 0.9308 & 0.9928 & 1.0471 & 1.0127 \\
I35 & 0.8648 & 1.0482 & 1.0109 & 0.9632 & 0.9986 & 1.0996 & 1.1460 & 1.3442 & 1.3108 & 1.1734 & 1.2443 & 1.2688 \\
I36 & 0.7317 & 0.8869 & 0.8553 & 0.8149 & 0.8980 & 0.9889 & 1.0306 & 1.2088 & 1.1787 & 1.0552 & 1.1189 & 1.1410 \\
I37 & 0.5657 & 0.6863 & 0.6615 & 0.6300 & 0.7501 & 0.8259 & 0.8608 & 1.0096 & 0.9845 & 0.8813 & 0.9346 & 0.9530 \\
I38 & 0.1551 & 0.1839 & 0.1722 & 0.1861 & 0.2197 & 0.2767 & 0.3158 & 0.3306 & 0.3659 & 0.3903 & 0.4116 & 0.3981 \\
I39 & 0.0507 & 0.0598 & 0.0530 & 0.0570 & 0.0530 & 0.0595 & 0.0670 & 0.0730 & 0.0750 & 0.0840 & 0.0790 & 0.0812 \\
I40 & 0.2257 & 0.2387 & 0.2373 & 0.2452 & 0.2739 & 0.2886 & 0.2900 & 0.2989 & 0.3062 & 0.3171 & 0.3434 & 0.3542 \\
\hline
\end{tabular}

Table A2. Estimation of output elasticity of human capital and intermediate-goods.

\begin{tabular}{|c|c|c|c|c|c|}
\hline Industry Code & $\begin{array}{l}\text { Output Elasticity } \\
\text { of Human Capital }\end{array}$ & $\begin{array}{l}\text { Output Elasticity of } \\
\text { Intermediate-goods }\end{array}$ & Industry Code & $\begin{array}{l}\text { Output Elasticity } \\
\text { of Human Capital }\end{array}$ & $\begin{array}{l}\text { Output Elasticity of } \\
\text { Intermediate-goods }\end{array}$ \\
\hline I1 & 0.3671 & 0.1791 & $\mathrm{I} 21$ & 0.2293 & 0.1042 \\
\hline $\mathrm{I} 2$ & 0.4303 & 0.2778 & $\mathrm{I} 22$ & 0.0501 & 0.1399 \\
\hline I3 & 0.2946 & 0.0488 & $\mathrm{I} 23$ & 0.2738 & 0.1357 \\
\hline I4 & 0.2662 & 0.1250 & $\mathrm{I} 24$ & 0.2955 & 0.1481 \\
\hline I5 & 0.1655 & 0.1385 & $\mathrm{I} 25$ & 0.1785 & 0.1388 \\
\hline I6 & 0.2078 & 0.1973 & I26 & 0.2111 & 0.0200 \\
\hline I7 & 0.1176 & 0.1623 & $\mathrm{I} 27$ & 0.2646 & 0.1370 \\
\hline I8 & 0.1997 & 0.1182 & $\mathrm{I} 28$ & 0.3036 & 0.1322 \\
\hline I9 & 0.2073 & 0.1364 & I 29 & 0.2241 & 0.1407 \\
\hline $\mathrm{I} 10$ & 0.2597 & 0.1215 & $\mathrm{I} 30$ & 0.1818 & 0.1194 \\
\hline I11 & 0.2436 & 0.1216 & I31 & 0.2044 & 0.1647 \\
\hline $\mathrm{I} 12$ & 0.4641 & 0.0832 & $\mathrm{I} 32$ & 0.2186 & 0.1443 \\
\hline I13 & 0.3352 & 0.1665 & I33 & 0.1771 & 0.1874 \\
\hline I14 & 0.3318 & 0.1274 & I34 & 0.3006 & 0.1429 \\
\hline $\mathrm{I} 15$ & 0.3497 & 0.1389 & I35 & 0.3896 & 0.0885 \\
\hline I16 & 0.3490 & 0.0970 & $\mathrm{I} 36$ & 0.1264 & 0.0881 \\
\hline I17 & 0.2735 & 0.1214 & I37 & 0.1384 & 0.1799 \\
\hline $\mathrm{I} 18$ & 0.3376 & 0.0715 & $\mathrm{I} 38$ & 0.2368 & 0.1467 \\
\hline I19 & 0.3652 & 0.0864 & I39 & 0.3178 & 0.1064 \\
\hline $\mathrm{I} 20$ & 0.2102 & 0.1260 & $\mathrm{I} 40$ & 0.4126 & 0.1523 \\
\hline
\end{tabular}

\section{References}

1. BP (British Petroleum). Statistical Review of World Energy. 2019. Available online: https://www.bp.com/zh_cn/china/home/ news/reports/statistical-review-2019.html (accessed on 11 October 2020).

2. Wang, Y.M. A new round of power transformation and path selection of China's economy. Manage. World. 2017, 2, 1-14.

3. Zhu, Z.Y. The power transformation and policy choice of China's economic growth. J. Quant. Tech. Econ. 2017, 34, 3-20. [CrossRef]

4. Zhao, C.W.; Xu, Z.Y.; Zhu, H.M. The new driving force of China economic growth in the late stage of industrialization. China Ind. Econ. 2015, 6, 44-54. [CrossRef]

5. Shen, K.R.; Cao, Y. Improving the quality of economic growth driven by innovation. Jiangsu Soc. Sci. 2017, 2, 50-55. [CrossRef]

6. Pan, W.; Pan, W.; Hu, C.; Tu, H.; Zhao, C.; Yu, D.; Xiong, J.; Zheng, G. Assessing the green economy in China: An improved framework. J. Clean. Prod. 2019, 209, 680-691. [CrossRef]

7. Liu, Y.; Dong, F. How technological innovation impacts urban green economy efficiency in emerging economies: A case study of 278 Chinese cities. Resour. Conserv. Recycl. 2021, 169, 105534. [CrossRef]

8. Yan, Z.; Zou, B.; Du, K.; Li, K. Do renewable energy technology innovations promote China's green productivity growth? Fresh evidence from partially linear functional-coefficient models. Energy Econ. 2020, 90, 104842. [CrossRef]

9. Mensah, C.N.; Long, X.; Dauda, L.; Boamah, K.B.; Salman, M.; Appiah-Twum, F.; Tachie, A.K. Technological innovation and green growth in the Organization for Economic Cooperation and Development economies. J. Clean. Prod. 2019, 240, 118204. [CrossRef]

10. Guo, L.L.; Qu, Y.; Tseng, M.-L. The interaction effects of environmental regulation and technological innovation on regional green growth performance. J. Clean. Prod. 2017, 162, 894-902. [CrossRef] 
11. Du, K.; Cheng, Y.; Yao, X. Environmental regulation, green technology innovation, and industrial structure upgrading: The road to the green transformation of Chinese cities. Energy Econ. 2021, 98, 105247. [CrossRef]

12. Hu, Z.; Ge, Y. The Geopolitical energy security evaluation method and a China case: Application based on politics of scale. Sustainability 2014, 6, 5682-5696. [CrossRef]

13. Fang, D.; Shi, S.; Yu, Q. Evaluation of sustainable energy security and an empirical analysis of China. Sustainability 2018, 10, 1685. [CrossRef]

14. Zhang, L.; Yu, J.; Sovacool, B.K.; Ren, J. Measuring energy security performance within China: Toward an inter-provincial prospective. Energy 2017, 125, 825-836. [CrossRef]

15. Sun, H.; Nie, F.F.; Hu, X.Y. Evaluation and difference analysis of energy security in China based on entropy weight TOPSIS modeling. Resour. Sci. 2018, 40, 477-485. [CrossRef]

16. Yang, Y.; Zheng, X.; Sun, Z. Coal resource security assessment in China: A study using entropy-weight- based TOPSIS and BP neural network. Sustainability 2020, 12, 2294. [CrossRef]

17. Romer, P.M. Endogenous technological change. J. Polit. Econ. 1990, 98, S71-S102. [CrossRef]

18. Tao, C.Q.; Peng, Y.Z. From factors driven to innovation driven: Switch of economic growth impetus and selection of pathway based on the perspective of institutional quality. J. Quant. Tech. Econ. 2018, 35, 3-21.

19. World Commission on Environment and Development. Our Common Future: Report of the World Commission on Environment and Development; Oxford University Press: Oxford, UK, 1987.

20. OECD. Declaration on Green Growth. Available online: https://www.oecd.org/environment/declarationongreengrowth.htm (accessed on 13 October 2020).

21. Jakob, M.; Edenhofer, O. Green growth, degrowth, and the commons. Oxf. Rev. Econ. Policy. 2015, 30, 447-468. [CrossRef]

22. OECD. Towards Green Growth. Available online: http://www.oecd.org/greengrowth/towards-green-growth-9789264111318en.htm (accessed on 13 October 2020).

23. International Energy Agency (IEA). Energy Technology Policy; OECD/IEA: Paris, France, 1985.

24. UNDP; UNDESA; WEC. World Energy Assessment: Overview 2004 Update. Available online: https://www.undp.org/content/ undp/en/home/librarypage/environment-energy/sustainable_energy/world_energy_assessmentoverview2004update/ (accessed on 13 October 2020).

25. Zhang, X.H.; Xiao, B. Energy security expectations, status quo preferences and the energy diplomacy decision-making of great powers. Contemp. Asiapac. Stud. 2011, 6, 95-122.

26. Moon, Y.S.; Sonn, Y.H. Productive energy consumption and economic growth: An endogenous growth model and its empirical application. Resour. Energy Econ. 1996, 18, 189-200. [CrossRef]

27. Considine, T.J.; Larson, D.F. The environment as a factor of production. J. Environ. Econ. Manag. 2006, 52, 645-662. [CrossRef]

28. Wang, F. Transition to a low-carbon economy under the constraints of fossil energy depletion and climate change. Mod. Econ. Sci. 2012, 34, 1-12.

29. Wang, Y.P. Energy sustainability, environment treatment and internal economic growth. Manag. World 2011, 4, 1-4. [CrossRef]

30. Chen, Z.L.; Wang, G.H.; Niu, W.Y. Economic growth model and empirical analysis under the constraint of energy and environment. Math. Pract. Theory 2013, 43, 46-53. [CrossRef]

31. Fève, P.; Guay, A. Identification of technology shocks in structural vars. Econ. J. 2010, 120, 1284-1318. [CrossRef]

32. Tahvonen, O.; Salo, S. Economic growth and transitions between renewable and nonrenewable energy resources. Eur. Econ. Rev. 2001, 45, 1379-1398. [CrossRef]

33. Xiao, W.; Tang, Z.Y. Renewable energy, quality of intermediate products and sustainable development. World. Econ. 2012, 35, 143-159.

34. Yan, X.X.; Zhang, J.S. The endogenous growth model under resources substitution, technological progress and environmental constraints. Math. Pract. Theory 2016, 46, 59-68.

35. Petschel-Held, G.; Schellnhuber, H.J.; Bruckner, T.; Tóth, F.L.; Hasselmann, K. The tolerable windows approach: Theoretical and methodological foundations. Clim. Chang. 1999, 41, 303-331. [CrossRef]

36. Zhang, B.; Zuo, H. Sustainable energy utilization, environmental governance and endogenous growth. China. Pop. Resour. Environ. 2007, 5, 27-32.

37. Wang, Q.X.; Cui, Y.Q.; Zhang, Y.G. Endogenous economic growth model under environment and energy constraints. J. Shandong. Univ. Nat. Sci. 2009, 44, 52-55.

38. Barro, R.J.; Sala-i-Martin, X. Economic Growth, 2nd ed.; McGraw-Hill: New York, NY, USA, 1995.

39. National Bureau of Statistics. Industrial Classification for National Economic Activities. Available online: http://www.stats.gov. cn/tjsj/tjbz/hyflbz/201710/t20171012_1541679.html (accessed on 13 July 2020).

40. Chen, S.Y. Reconstruction of sub-industrial statistical data in China (1980-2008). China Econ. Q. 2011, 10, 735-776. [CrossRef]

41. Fan, G.; Wang, X.L.; Ma, G.R. Contribution of marketization to China's economic growth. Econ. Res. J. 2011, 46, 4-16.

42. Yao, X.; Zhang, W.J.; Wang, F.W. Estimation and analysis of China's natural interest rate. Chin. Rev. Financ. Stud. 2019, 11, 15-29+123.

43. Lu, J.; Zhao, Y.N.; Chen, Y. Research on the influence mechanism of human capital and technological innovation on environmental pollution: An empirical study based on 285 cities across the country. Resour. Environ. Yangtze. Basin. 2019, 28, 2186-2196. [CrossRef] 
44. Wang, L.H.; Wang, H.; Dong, Z.Q. Policy conditions of compatibility between economic growth and environmental quality. Manag. World. 2020, 36, 39-60. [CrossRef]

45. Jiang, S.L.; Liu, H. Impact of technological progress on regional environmental quality in China: Based on the perspective of pollution emissions. J. Cent. South. Univ. For. Technol. Soc. Sci. 2017, 11, 5-11. [CrossRef]

46. Huang, Z.L. A study on business cycle and the effects of fiscal policy in China: An empirical study on a RBC model with three sections. Econ. Res. J. 2005, 6, 27-39.

47. Kunanuntakij, K.; Varabuntoonvit, V.; Vorayos, N.; Panjapornpon, C.; Mungcharoen, T. Thailand green GDP assessment based on environmentally extended input-Output model. J. Clean. Prod. 2017, 167, 970-977. [CrossRef]

48. Zeng, S.; Jiang, X. China's $\mathrm{SO}_{2}$ shadow prices and environmental technical efficiency at the province level. Int. Rev. Econ. Financ. 2018, 57, 86-102. [CrossRef]

49. Xie., H.; Yu, Y. The substitutability of non-fossil energy, potential carbon emission reduction and energy shadow prices in China. Energy Policy 2017, 107, 63-71. [CrossRef]

50. Chen, Q. Advanced Econometrics and Stata Application, 2nd ed.; Higher Education Press: Beijing, China, 2014.

51. Hansen, B.E. Threshold effects in non-dynamic panels: Estimation, testing, and inference. J. Econ. 1999, 93, 345-368. [CrossRef]

52. Li, M.; Liu, S.C. Regional differences and threshold effect of reverse technology spillover of FDI: A threshold regression analysis based on China's provincial panel data. Manag. World 2012, 1, 21-32+66. [CrossRef]

53. Xu, W. Macroeconomics, 1st ed.; Zhejiang Gongshang University Press: Hangzhou, China, 2015; pp. 7-37.

54. Lin, B.Q.; Jiang, Z.J. A forecast for China's environmental Kuznets curve for $\mathrm{CO}_{2}$ emission, and an analysis of the factors affecting China's $\mathrm{CO}_{2}$ emission. Manag. World 2009, 4, 27-36. [CrossRef]

55. Fu, H.; Mao, Y.S.; Song, L.S. Empirical analysis on the effect of innovation on advancement of industrial structure process: Based on panel data of provinces from 2000 to 2011. Chin. Ind. Econ. 2013, 9, 56-68.

56. Lao, K.F. Research on mechanism of consumer innovativeness influences green consumption behavior. Nankai Bus. Rev. 2013, 16, 106-113,132. [CrossRef]

57. Sun, Z.; Liu, L.H. Social security, entrepreneurship and endogenous economic growth. Stat. Res. 2019, 36, 77-91. [CrossRef]

58. Zhao, D.S.; Kou, Y.; Zhang, J.M. Business environment and green economic growth: Based on the mediating effect and masking effect of entrepreneurship. Inq. Econ. Iss. 2021, 2, 66-77.

59. Sohag, K.; Taşkın, F.D.; Malik, M.N. Green economic growth, cleaner energy and militarization: Evidence from Turkey. Resour. Policy 2019, 63, 101407. [CrossRef]

60. Ahmad, M.; Jiang, P.; Murshed, M.; Shehzad, K.; Akram, R.; Cui, L.; Khan, Z. Modelling the dynamic linkages between ecoinnovation, urbanization, economic growth and ecological footprints for G7 countries: Does financial globalization matter? Sustain. Cities Soc. 2021, 70, 102881. [CrossRef]

61. Xie, X.J.; Wang, X.F.; Ren, X.G. The influence of marketization on green total factor productivity. J. Beijing Inst. Technol. Soc. Sci. Ed. 2021, 23, 67-78. [CrossRef]

62. Acemoglu, D.; Aghion, P.; Bursztyn, L.; Hemous, D. The environment and directed technical change. Amer. Econ. Rev. 2012, 102, 131-166. [CrossRef] [PubMed]

63. Shen, K.R.; Jin, G.; Fang, X. Does environmental regulation cause pollution to move nearby? Econ. Res. 2017, 5, 44-59.

64. Yuan, B.; Xiang, Q. Environmental regulation, industrial innovation and green development of Chinese manufacturing: Based on an extended CDM model. J. Clean. Prod. 2018, 176, 895-908. [CrossRef]

65. Zhao, X.G.; Liu, P.K. Economic growth and energy intensity: An empirical research based on panel smooth transition regression model. Chin. J. Manag. Sci. 2014, 22, 103-113. [CrossRef]

66. Fan, Q. Analyzing on factor-intensive type of trades in a perspective of Rybczynski theorem: Data from 36 different trades of the industry sector in China. Ind. Technol. Econ. 2012, 31, 57-65. [CrossRef]

67. Wang, Y.L.; Li, Q. Openness and China industrial energy efficiency: Based on industrial panel data. J. Beijing Inst. Technol. Soc. Sci. Ed. 2012, 14, 27-33. [CrossRef]

68. Cao, F. Oil price shocks and China's actual economic fluctuations: An RBC model analysis. Chin. J. Manag. Sci. 2015, 23, 45-52. [CrossRef]

69. Han, J.; Zhang, H.N. Measurement of regional energy consumption under the background of economic high-quality development in China. J. Quant. Tech. Econ. 2019, 36, 42-61. [CrossRef]

70. Karatayev, M.; Hall, S. Establishing and comparing energy security trends in resource-rich exporting nations (Russia and the Caspian Sea region). Resour. Policy 2020, 68, 101746. [CrossRef]

71. Li, J.J.; Hu, P. Study on consumer-driven converting of economic growth pattern: Theoretical framework of consumer participation. Res. Econ. Manag. 2012, 9, 33-40. [CrossRef]

72. Dixit, A.K.; Stiglitz, J.E. Monopolistic competition and optimum product diversity. Amer. Econ. Rev. 1997, 67, $297-308$.

73. Goldsmith, R.W. A Perpetual Inventory of National Wealth; National Bureau of Economic Research, Inc.: Cambridge, MA, USA, 1951; pp. 5-6. 